\title{
The determinants of regional freight transport: a spatial, semi-parametric approach
}

\author{
Tamás Krisztin*
}

\begin{abstract}
In the context of modeling regional freight the four-stage model is a popular choice. The first stage of the model, freight generation and attraction, however, suffers from three shortcomings: first of all, it does not take spatial dependencies among regions into account, thus potentially yielding biased estimates. Second, there is no clear consensus in the literature as to the choice of explanatory variables. Secondly, sectoral employment and gross value added are used to explain freight generation, whereas some recent publications emphasize the importance of variables which measure the amount of logistical activity in a region. Third, there is a lack of consensus regarding the functional form of the explanatory variables. Multiple recent studies (Hesse and Rodrigue, 2004; Ranaiefar et al., 2013; Rodrigue, 2006; Tavasszy et al., 2012) emphasize nonlinear influences of selected variables. This paper addresses these shortcomings by using a spatial variant of the classic freight generation and attraction models combined with a penalized spline framework to model the explanatory variables in a semi-parametric fashion. Moreover, a Bayesian estimation approach is used, coupled with a penalized Normal inverse-Gamma prior structure, in order to introduce uncertainty regarding the choice and functional form of explanatory variables. The performance of the model is assessed on a real world example of freight generation and attraction of 258 European NUTS-2 level regions, covering 25 European countries.
\end{abstract}

Keywords: freight transportation, semi-parametric modeling, Bayesian econometrics, spatial autoregressive models

JEL Classification: C11, C14, C21, O18, R12, R40

October 12, 2016

\section{Introduction}

The four-stage model of regional transportation planning is a popular approach to assess the requirements for transportation and to adjust transportation policy. The model's first stage freight generation and attraction - concerns the total volume of freight originating from or flowing to regions, respectively. This basic model has been a popular tool to explain and project the demand for transportation in a regional setting (see, e.g. Novak et al. 2008 or Ranaiefar et al.

*International Institute for Applied Systems Analysis, IIASA; E-mail address: krisztin@iiasa.ac.at 
2013). In its original form - described, for example, in Ortúzar and Willumsen (2011) - freight generation and attraction models are simple linear regression models, where a region's sectoral, economic and demographic characteristics are regressed on the volume of freight generated and attracted, respectively, in the observation period.

This basic model of freight generation and attraction, however, suffers from a number of crucial shortcomings. First and foremost, it does not take the spatial nature of freight generation and attraction into account. Both in freight generation and attraction, spatial dependencies can arise, e.g. by neighboring regions influencing each others' volume of freight. These spatial dependencies can be the result of stronger economic ties between neighboring regions, e.g. if manufacturing plants are located in regions neighboring urban regions (De Grange et al., 2010). Recent modeling approaches in freight generation and attraction have found such spatial patterns. Hence Novak et al. (2008) and others use a spatial autoregressive model specification, introduced by Anselin (1988) to account for spatial lags of the variables. Their results indicate that spatial spillovers play a significant role in both freight generation and attraction.

A second problem associated with regional freight generation and attraction is the choice of explanatory variables in these models. The classic models include gross regional product and employment indicators for both freight generation and attraction. In the case of freight generation, sectoral gross value added and employment in manufacturing are considered to be relevant explanatory variables. For freight attraction, demand for final products can be proxied by the total population and intermediate demand is included as sectoral gross value added. These variables have been challenged by Hesse and Rodrigue (2004), Rodrigue (2006) and Tavasszy et al. (2012), among others. They argue for including variables that measure the regional intensity of logistic activities, in terms of the share of logistic companies or the average size of logistic and distribution companies. Novak et al. (2008), and Sánchez-Díaz et al. (2016) stress the importance of variables that characterize the geographical infrastructure, and suggest using the distance to ports or the length of highways in a region, while Chow et al. (2010), Boerkamps et al. (2000), Wisetjindawat and Sano (2003) and Wagner (2010) draw attention to land-use indicators as proxy for logistical activity, arguing that a higher share of developed surfaces in a region indicates a higher volume of generated and attracted freight. Nevertheless, it seems unclear, which explanatory variables to include in models of freight generation and attraction.

Including a full selection of all proposed explanatory variables would substantially reduce the degrees of freedom in a regional economic setting and potentially cause problems with multicollinearity of the explanatory variables. Multiple studies (Ranaiefar et al., 2013; Tavasszy et al., 2012) in freight generation address this issue by manually selecting the subset of variables which yield the best chosen measure of fit (for example using $R^{2}$ or the Akaike Information Criterion as measures). Such an approach might not be optimal, as - even with a moderate number of co-variates - testing all possible combinations might not be feasible. Only testing a subset of the models might lead to biased choices of variables (Fahrmeir et al., 2004).

Such variable selection issues may be addressed through using Bayesian techniques (LeSage and Parent, 2007; Piribauer and Fischer, 2015). Instead of having to select a single set of explanatory variables, Bayesian variable selection approaches advocate using a model with a wide selection of different variables, and through an adequate selection of priors, using the posterior importance of variables for inference. In this fashion a large number of potential explanatory variables can be included and parameter inference can be made unconditional on model specifications. There is a wide array of literature on variable selection in non-spatial frameworks (e.g. see Koop 2003, George and McCulloch 1993 and Kuo and Mallick 1998), and various approaches to incorporate variable selection into a spatial framework (see, for example, Lesage and Fischer, 2009).

A third shortcoming of the freight generation and attraction models lies in the uncertainty over which functional form to use for the explanatory variables. Sánchez-Díaz et al. (2016) suggest multiple nonlinear transformations (for example logarithmic, quadratic or exponential transformations, as in Novak et al. 2008) of the explanatory variables, until a sufficient value of the chosen measure of fit is achieved. As noted by Tavasszy et al. (2012) and Rodrigue (2006) such an exploratory approach shows some drawbacks: first, it is difficult to specify which functional form would be the most appropriate for each variable. Second, testing for a wide number of transformations can be computationally burdensome and including polynomials of high order can lead to numerical instability. 
Such nonlinearities in the parameters, however, seem to play a central role in freight generation and attraction. Even in the case of freight generation and attraction models that account for spatial dependence the transformation of variables can improve the model fit (Novak et al., 2008). Chow et al. (2010), and De Jong et al. (2013) among others address this issue by means of a semi-parametric approach. Ranaiefar et al. (2013) suggest using a structural equation modelling approach to capture these effects, their model, however suffers from a number of key weaknesses. First, while they take the spatial nature of freight generation into account, they only include spatial lags of the explanatory variables, not of the dependent variable. Second, their structural equation model does not explicitly differentiate between spatial correlation and nonlinearities in the data, instead it subsumes this into joint correlation estimates, which capture any additional nonlinearity. Moreover, structural equation modelling usually requires large data samples to perform adequately, which makes it ill suited for the modelling of regional freight generation.

Semi-parametric modeling in the context of spatial autoregressive models was recently addressed by Basile (2008), Del Bo and Florio (2012), Fotopoulos (2012) and Basile et al. (2014). The advantage of the semi-parametric approach, relying on the parametric expansion of co-variates through spline functions, is that it can be easily used in conjunction with classical spatial econometric estimation approaches. The main drawback of this approach is that in a frequentist context, it is often difficult to estimate, due to the increased number of effective parameters ${ }^{1}$. While frequentist solutions such as penalized least-squares exist (Eilers and Marx, 1996), these are typically outperformed by Bayesian estimation methods relying on some form of shrinkage priors (Lang and Brezger, 2004). Moreover, Bayesian estimation methods can potentially be combined with the aforementioned Bayesian variable selection approaches. This was recently proposed (albeit in a non-spatial context) in Brezger and Lang (2006); Fahrmeir et al. (2004); Lang and Brezger (2004) by using random-walk priors for the splines, in conjunction with spike-and-slab priors for the selection of explanatory variables.

This paper aims to address three central issues associated with freight generation and attraction modeling. First, it is increasingly recognized that freight generation (and attraction) is a spatial process, characterized by spatial dependencies. Neglecting these dependencies would lead to biased and incorrect estimates. To address this issue, our approach takes spatial lags of the dependent and the explanatory variables into account. Second, we address the issue of uncertainty arising from explanatory variable selection. For this purpose we use a Bayesian variable selection framework, using spike-and-slab priors, which can consider models including a potentially large number of covariates and provides posterior evidence on the relative importance of explanatory variables. Third, it is the linearity in parameters in conventional linear regression models that greatly simplifies the analysis of this class of models. But it also leads to some significant limitations. Since previous literature suggests that such nonlinearities could play an important role in the modeling of freight generation, we relax the assumption of linearity through a novel Bayesian semi-parametric modeling approach. This enables us to test for the presence or absence of nonlinearity in the impact of the explanatory variables.

In summary, this paper contributes in multiple ways to the literature: it presents a novel spatial, semi-parametric modeling approach in conjuction with variable selection. To our knowledge, no other modeling approach allows for simultaneous inference on the relative importance of co-variates, their functional form, as well as the strength of spatial dependencies of the response variable. Moreover, in the context of freight generation and attraction modeling, this paper addresses the questions, whether there is significant spatial dependence in the volume of freight generated by (or attracted to) European regions, what the central explanatory variables of freight generation (or attraction) are, and finally whether these variables have a nonlinear impact on freight generation (or attraction).

The rest of the paper is organized as follows. Section 2 presents the basic freight generation and attraction model, together with its spatial counterpart. Section 3 expands the spatial version of the model by introducing nonlinearity in the parameters through basic splines and discussing the penalized spline structure. In section 4 we continue the prior set-up, and present the full

\footnotetext{
${ }^{1}$ Consider, that a parametric expansion relies on splitting each co-variate into a set of basis functions, which effectively multiplies the number of co-variates by the number of basis functions used for the expansion. Even a comparatively low number of basis functions (e.g. five to ten), would result in five to ten times as many parameters in the semi-parametric model.
} 
conditional posteriors and the sampling procedure employed in the Bayesian estimation of the model.

Section 5 serves to test the proposed model approach using an empirical example of freight generation and attraction with 258 European NUTS-2 level regions, that cover the EU-27 countries, excluding Cyprus and Malta. We model the average freight generation and attraction in the period 2010-2014, based on a selection of 20 covariates and their spatially lagged counterparts. Out of these variables we model 14 (and their spatially lagged counterparts) in a semi-parametric fashion. The results indicate that spatial spillovers play a significant role, and that in the case of sectoral manufacturing variables a nonlinear parametrization should be used. Section 6 concludes.

\section{The spatial freight generation and attraction models}

Let $y_{i}$ denote the volume of freight generated by (or attracted to) region $i(i=1, \ldots, N)$, where $N$ is the number of regions in the study area. The model postulates that $y_{i}$ can be explained by a $1 \times K$ vector $\boldsymbol{x}_{i}$, containing observations on $K$ socio-economic characteristics, with an $K$ by 1 vector of associated coefficients $\boldsymbol{\theta}$, an intercept $\theta_{0}$, and an error term $\boldsymbol{\varepsilon}_{i}$, assumed to be normally and identically distributed for all $i$, with zero mean and $\sigma^{2}$ variance. Thus we can write:

$$
\begin{aligned}
& y_{i}=\theta_{0}+\boldsymbol{x}_{i} \boldsymbol{\theta}+\varepsilon_{i} \\
& \varepsilon_{i}=\mathcal{N}\left(0, \sigma^{2}\right) .
\end{aligned}
$$

The linear regression model in Eq. (1) is referred to as the basic freight generation (or attraction) model (De Grange et al., 2013).

In freight generation and attraction models spatial dependence may arise in two ways, first, by neighboring regions influencing the volume of freight generated or attracted by a given region, and second by spatially dependent explanatory variables - such as land-use or population characteristics (Anselin and Bera, 1998; Arbia, 2006). To account for these spatial dependencies we use a spatial Durbin model (SDM) specification (LeSage and Pace, 2009). This can be written as:

$$
y_{i}=\rho \sum_{q=1}^{N} w_{i, q} y_{q}+\theta_{0}+\boldsymbol{x}_{i} \boldsymbol{\theta}+\sum_{q=1}^{N} w_{i, q} \boldsymbol{x}_{q} \boldsymbol{\lambda}+\varepsilon_{i} .
$$

$w_{i, q}$ (with $\left.q=1, \ldots, N\right)$ is a typical element of the $N$ by $N$ exogenously given non-negative spatial weight matrix $\mathbf{W}$. If observations $i$ and $q$ are considered to be neighbors, then $w_{i, q}>0$, otherwise $w_{i, q}=0$, with $w_{i, q \mid i=q}=0$ (meaning that no observation is a neighbor to itself). $\mathbf{W}$ is assumed to be row-stochastic, so that $\sum_{q} w_{i, q}=1 \forall q=1, \ldots, N$ (Fischer and Wang, 2011).

The term $w_{i, q} y_{q}$ describes an endogenous interaction effect among the dependent variable, the term $w_{i, q} \boldsymbol{x}_{q}$ exogenous interaction effect among the independent variables. $\rho \in[-1,1]$ is called the spatial autoregressive coefficient, while $\boldsymbol{\lambda}$ - just as $\boldsymbol{\theta}$ - represents a $K \times 1$ vector of fixed, but interlinked parameter vector. Note that Eq. (2) subsumes Eq. (1) as a special case, if $\rho=0$ and $\lambda_{1}, \ldots, \lambda_{K}=0$.

To simplify our notation, we rewrite Eq. (2) in matrix notation. Let $\boldsymbol{y}=\left[y_{1}, \ldots, y_{N}\right]^{\prime}$ and let the $N$ by $2 K$ matrix $\mathbf{V}=[\mathbf{X}, \mathbf{W X}]$, where $\mathbf{X}=\left[\boldsymbol{x}_{1}^{\prime}, \ldots, \boldsymbol{x}_{N}^{\prime}\right]^{\prime}$ is the $N$ by $K$ matrix of explanatory variables. In this way we can re-write Eq. (2) as:

$$
\begin{aligned}
& \boldsymbol{y}=\rho \mathbf{W} \boldsymbol{y}+\iota_{N} \theta_{0}+\mathbf{V} \boldsymbol{\phi}+\boldsymbol{\varepsilon} \\
& \boldsymbol{\varepsilon}=\mathcal{N}\left(0, \sigma^{2} \mathbf{I}_{N}\right)
\end{aligned}
$$

where $\boldsymbol{\phi}=\left[\boldsymbol{\theta}^{\prime}, \boldsymbol{\lambda}^{\prime}\right]^{\prime}, \boldsymbol{\iota}_{N}$ denotes an $N \times 1$ vector of ones, and $\mathbf{I}_{N}$ is an $N \times N$ identity matrix.

One important feature of models accounting for spatial dependence is that the interpretation of the partial derivatives becomes richer but more complicated. In classical freight generation and attraction models, such as in Eq. (1), the partial derivatives of $y_{i}$ with respect to $x_{i k}$ have the simple form where $\frac{\partial y_{i}}{\partial x_{i k}}=\theta_{k}$ and $\frac{\partial y_{i}}{\partial x_{j k}}=0$ for all $i \neq j$ and all $k=(1, \ldots, K)$ variables. However in the spatial dependence case with $\rho \neq 0$ and $\lambda_{k} \neq 0$, the interpretation of the partial derivatives becomes richer but more complicated. We follow (LeSage and Pace, 2009) and use summary impact measures to asses the average direct, indirect and total impact of changes in the $k$-th $\boldsymbol{x}$ model variable. 


\section{Semi-parametric modeling of freight generation and at- traction}

While the model in Eq. (3) can capture nonlinearities associated by spatial patterns, as pointed out by Rodrigue (2006) freight generation models may contain further nonlinearities in the explanatory variables as well, which are non-spatial in nature. We address this issue by following a strain of literature from regional economic growth models, which combines spatial models and semi-parametric modeling. This approach, pioneered by Basile (2008); Basile et al. (2014); Del Bo and Florio (2012); Fotopoulos (2012), is characterized by the use of a univariate smoothing function that allows a more flexible modeling of the explanatory variables and thus capture potential nonlinearities in the parameters. These papers use a form of parameter expansions called basic splines $^{2}$ (B-splines), based on locally defined piece-wise polynomials, to model explanatory variables in a flexible way (Ruppert et al., 2003).

\section{Semi-parametric modeling via B-Splines}

To capture potential nonlinear influences of the explanatory variables on the dependent variable in Eq. (3) we assume a continuous function $f_{m}($.$) for the set of explanatory variables:$

$$
\begin{aligned}
\boldsymbol{y} & =\rho \mathbf{W} \boldsymbol{y}+\boldsymbol{\iota}_{n} \theta_{0}+\boldsymbol{f}(\mathbf{V})+\boldsymbol{\varepsilon} \\
\boldsymbol{f}(\mathbf{V}) & =\sum_{m=1}^{2 K} f_{m}\left(\boldsymbol{v}_{m}\right)
\end{aligned}
$$

where $\boldsymbol{v}_{m}$ (with $m=1, \ldots, 2 K$ ) denotes the $m$-th column of $\mathbf{V}$ and the exact functional form of each $f_{m}(\cdot)$ is unknown. $f_{m}(\cdot)$ is assumed to be a smooth function with continuous first order derivatives. Continuous derivatives are essential for calculating the direct and indirect spatial summary impact measures.

Following Lang and Brezger (2004), we model the unknown functions $f_{m}(\cdot)$ through B-Splines, introduced by Eilers and Marx (1996). The core assumption underlying this approach is that we can approximate $f_{m}(\cdot)$ through a set of piecewise polynomials, each of $D_{m}$-th degree, and defined over $P_{m}$ knots, denoted as $\chi_{m}$. The $L_{m}$ elements of $\chi_{m}$ are equally spaced over the range spanned by $\min \left(\boldsymbol{v}_{m}\right)$ and $\max \left(\boldsymbol{v}_{m}\right)$ [where $\min \left(\boldsymbol{v}_{m}\right)$ denotes the smallest and $\max \left(\boldsymbol{v}_{m}\right)$ the largest element of $\boldsymbol{v}_{m}$, respectively]. Each knot $\chi_{m, p_{m}} \in \chi_{m}$ (with $p_{m}=1, \ldots, P_{m}$ ) is a support point for the $p_{m^{-}}$ th piecewise polynomial. Each piecewise polynomial is defined over the range of exactly $D_{m}$ knots and are zero otherwise. If we let the $l p_{m}$-th column of the $N \times P_{m}$ design matrix $\overline{\mathbf{Z}}_{m}$ correspond to the splines representation of the $p_{m}$-th polynomial (as defined in the seminal work by DeBoor 1978; for details see Appendix A, we can rewrite $f_{m}(\cdot)$, so that:

$$
f_{m}\left(\boldsymbol{v}_{m}\right)=\overline{\mathbf{Z}}_{m} \overline{\boldsymbol{\beta}}_{m}
$$

The unknown function $f_{m}\left(\boldsymbol{v}_{m}\right)$ models $m$-th explanatory variable in a semi-parametric fashion, through a so-called design matrix $\overline{\mathbf{Z}}_{m}$ and $\overline{\boldsymbol{\beta}}_{m}$, a $P_{m} \times 1$ vector of corresponding coefficients. The bars above the terms $\overline{\mathbf{Z}}_{m}$ and $\overline{\boldsymbol{\beta}}_{m}$ signify that the terms are associated with parameter expanded basis functions. The number of columns of the design matrix $P_{m}=L_{m}+2 D_{m}$ corresponds exactly to the number of knots and twice the degree of the spline. The $D_{m}$ extra columns, termed as so-called support knots in the spline literature, define the spline outside of $\boldsymbol{v}_{m}^{\text {min }}$ and $\boldsymbol{v}_{m}^{\text {max }}$. For details, see Appendix A.

The derivatives of a B-spline, represented through $P_{m}$ piecewise polynomials of degree $D_{m}$ over $P_{m}$ support knots, can in turn be expressed by piecewise polynomials of degree $D_{m}-1$ over the same support knots. Similar to the representation of the B-spline above, we can express its first order derivatives in terms of an $N \times P_{m}$ design matrix $\overline{\mathbf{Z}}_{m}^{\partial}$ and the vector of coefficient $\overline{\boldsymbol{\beta}}_{m}$, where $\partial$ signifies that the matrix $\overline{\mathbf{Z}}_{m}^{\partial}$ represents first-order derivatives. For details on the construction of the matrix $\overline{\mathbf{Z}}_{m}^{\partial}$ of partial derivatives, see DeBoor (1978).

\footnotetext{
${ }^{2}$ Basic splines are a class of semi-parametric basis function, which can be used to model nonlinearities in the parameter. This is achieved by using a large set of overlapping piecewise polynomials (the so-called bases) to model each explanatory variables (DeBoor, 1978).
} 
Based on the fully specified representation of $f_{m}(\cdot)$ in Eq. (5), we can rewrite Eq. (4) as:

$$
\boldsymbol{y}=\rho \mathbf{W} \boldsymbol{y}+\boldsymbol{\eta}_{0}+\sum_{m=1}^{2 K} \overline{\mathbf{Z}}_{m} \overline{\boldsymbol{\beta}}_{m}+\boldsymbol{\varepsilon}
$$

where $\boldsymbol{\eta}_{0}=\mathbf{X}_{0} \boldsymbol{\beta}_{0}$. The $N \times K_{0}$ matrix $\mathbf{X}_{0}$ contains the intercept and other variables which we do not want to model in a semi-parametric fashion (for example fixed or random effects). $\boldsymbol{\beta}_{0}$ is the $K_{0} \times 1$ vector of corresponding coefficients. ${ }^{3}$

It is easy to see from Eq. (6) that the B-spline model is similar to the SAR model discussed in the previous section, but with a large number of additional coefficients. The calculation of summary statistics for direct, indirect and total partial derivatives presents a slight departure from the SAR model, since the first-order derivatives of B-splines are not equal to the coefficients. Let the modified total derivative matrix, which includes the correct derivatives for B-splines, be denoted as $\mathbf{S}_{k}(\mathbf{W})$. Then, we can write:

$$
\begin{aligned}
\frac{\partial y_{i}}{\partial x_{j k}} & =\mathbf{S}_{k}(\mathbf{W})_{i j} \text { and } \frac{\partial y_{i}}{\partial x_{i k}}=\mathbf{S}_{k}(\mathbf{W})_{i i} \\
\mathbf{S}_{k}(\mathbf{W}) & =\left(\mathbf{I}_{n}-\rho \mathbf{W}\right)^{-1}\left[\operatorname{diag}\left(\frac{\partial f_{k}\left(\boldsymbol{x}_{k}\right)}{\partial \boldsymbol{x}_{k}}\right)+\operatorname{diag}\left(\frac{\partial f_{k}\left(\mathbf{W} \boldsymbol{x}_{k}\right)}{\partial \boldsymbol{x}_{k}}\right)\right]
\end{aligned}
$$

where the $\operatorname{diag}(\cdot)$ operator transforms a vector into a matrix, with the vectors' values along the main diagonal. Based on $\mathbf{S}_{k}(\mathbf{W})$, we can compute the summary direct, indirect and total effects in the same fashion as in LeSage and Pace (2009).

The B-spline model can be estimated in a similar fashion as the SAR model. It is, however, very likely that the model in Eq. (6) is over-specified, since the total number of coefficients $\left(\sum_{m=1}^{M} P_{m}+K_{0}+1\right)$ is quite likely to come close or even exceed $N$. This is obviously dependent on the total number of support knots $\sum_{m} P_{m}$. If we choose a large number (for example ten or more) of equally spaced knots, we are rather flexible in the choice of functional form for $\boldsymbol{f}(\cdot)$. If we only use relatively few knots, we might be too inflexible and our particular parametrization might not adequately capture prevalent nonlinearities. While the B-spline representation in Eq. (6) clearly allows for additional flexibility in modeling the impacts of the explanatory variables, this comes at the cost of the so-called curse of dimensionality; the more flexible our modeling approach, the more observations would be needed. In most regional studies, observations are limited to crosssectional and panel data contexts, usually comprising not more than 1,000 observations. This, of course, severely restricts the number of covariates that could be modeled with simple B-splines alone.

\section{Penalized splines}

The ability of splines to correctly approximate the continuous nonlinear function $f_{m}(\cdot)$ is dependent on the number of spline knots $L_{m}$. Furthermore, selecting a large number of spline knots raises the issues of over-parametrization and over-fitting, while selecting too few could mean that we do not approximate $f_{m}(\cdot)$ to a sufficient degree using B-splines. Multiple approaches have been proposed to deal with this problem. As suggested by Koop and Poirier (2004), one could vary the number of design knots in order to minimize certain criteria, for example the AIC or the Bayes' factor. This approach, however, usually show rather slow convergence, if the number of explanatory variables is increased. To circumvent this problem, we allow for a relatively large number of uniformly placed knots and follow Eilers and Marx (1996) to utilize a penalized estimation procedure, termed Psplines.

This approach applies the concepts of Bayesian shrinkage to the B-spline model and assumes a random walk structure for the parameter vector $\overline{\boldsymbol{\beta}}_{m}$ (for $\left.1, \ldots, M\right)$, where the conditional expectation of $\overline{\boldsymbol{\beta}}_{p_{m}, m}$ is dependent on $\overline{\boldsymbol{\beta}}_{p_{m}-1, m}$ (Eilers and Marx, 1996). More formally, and assuming a random walk structure of order one:

$$
p\left(\overline{\boldsymbol{\beta}}_{p_{m}, m} \mid \overline{\boldsymbol{\beta}}_{p_{m}-1, m}, \ldots, \overline{\boldsymbol{\beta}}_{1, m}\right) \sim \mathcal{N}\left(\overline{\boldsymbol{\beta}}_{p_{m}-1, m}, \tau_{m}^{2}\right) \quad p_{m}=1, \ldots, P_{m}
$$

\footnotetext{
${ }^{3}$ Note that in Eq. (6) the mean levels of the smooth functions $f_{m}(\cdot)$ are not identifiable. To ensure identifiability all basis functions $f_{m}(\cdot)$, and thus all design matrices $\overline{\mathbf{Z}}_{m}$ are constrained to have zero mean.
} 
where the coefficient $\tau_{m}^{2}$ is a measure of the $m$-th random walk's variance. On the one hand, if $\tau_{m}^{2}$ is large, the B-spline coefficients associated with each of the $p_{m}$ piecewise polynomials in $\overline{\mathbf{Z}}_{m}$ are allowed to differ to a large degree, which leads to larger variances in the functional form of the resulting splines. If, on the other hand, $\tau_{m}^{2}$ is relatively small, the coefficients in $\overline{\boldsymbol{\beta}}_{m}$ will be very closely associated with each other, which leads to a nearly linear functional form for $f_{m}(\cdot)$.

This random walk structure for $p\left(\overline{\boldsymbol{\beta}}_{m} \mid \tau_{m}^{2}\right)$ can be incorporated by reparametrizing the design matrices $\overline{\mathbf{Z}}_{m}$ in Eq. (6), so that they include the random walk specification (Scheipl et al., 2012). We use the reparametrization based on spectral decomposition, as suggested in Fahrmeir et al. (2004) and earlier semiparametric approaches, such as in Lang and Brezger (2004), and Ruppert et al. (2003). This procedure relies on decomposing $f(\cdot)$, into the separate function $f_{0}(\cdot)$ and $f_{\text {pen }}(\cdot)$. The function $f_{0}(\cdot)$ spans the null-space of $f(\cdot)$ and can be interpreted as it's linear part component. $f_{\text {pen }}(\cdot)$ represents the penalized part of $f(\cdot)$, and can be interpreted as it's nonlinear components. Based on this reparametrization approach, and coupled with Bayesian variable selection priors, we can infer whether the linear or the nonlinear, or both parts of the splines have a higher posterior probability of being included in our models.

Based on this reasoning, let us assume that reparametrization has been applied to all $2 \mathrm{~K}$ semiparametric model terms, thus yielding $4 K$ model terms. We might, moreover, wish to include $K_{\text {lin }}$ explanatory variables as model terms, which should not be modeled in a semi-parametric fashion, but we still want to make inference over their inclusion probability. Together, this adds up to $Q=4 K+2 K_{\text {lin }}$ separate model terms, where we denote the $j$-th model term (whether it is a penalized or unpenalized matrix) by the $n \times P_{j}$ design matrix $\mathbf{Z}_{j}$, with $j=1, \ldots, Q$, with corresponding $P_{j} \times 1$ parameter vector $\boldsymbol{\beta}_{j}$. Thus we can write

$$
\boldsymbol{y}=\rho \mathbf{W} \boldsymbol{y}+\boldsymbol{\eta}_{0}+\sum_{j=1}^{Q} \mathbf{Z}_{j} \boldsymbol{\beta}_{j}+\boldsymbol{\varepsilon}
$$

where, due to the reparametrization, $p\left(\boldsymbol{\beta}_{j} \mid \tau_{j}^{2}\right) \sim \mathcal{N}\left(0, \tau_{j}^{2} \mathbf{I}_{N}\right)$.

To sum up, the reparametrization serves three main purposes: first, it naturally incorporates the above random walk prior into the model formulation itself; second, it enables us to separate each smooth polynomial term into an unpenalized and a penalized part. This in turn makes it possible to evaluate whether a penalized term should be included in the model at all, or whether the null-space of the explanatory variable (i.e. in the case of a first order random walk penalization structure its linear form) is sufficient. Thus we can obtain inference over the linearity of individual explanatory variables. Third, the reparametrization makes prior elicitation easier, since the reparametrized term has a proper Gaussian distribution, whereas the random-walk parametrization is improper (Scheipl et al., 2012).

\section{Bayesian estimation}

We follow a Bayesian approach in estimating Eq. (9). This is motivated by the usefulness of penalized splines in circumventing problems of dimensionality through a random-walk prior as in Eq. (8) and its re-parameterized counterpart. Moreover, a Bayesian approach allows us to make use of so-called variable selection priors. Such a prior structure allows for inference over the posterior inclusion probability of our explanatory variables. Thus, we can easily address the issue of uncertainty, whether, for example, supply-chain variables influence freight generation and attraction. We incorporate this into our model by using a penalized Normal inverse-Gamma prior set-up, in the spirit of Scheipl et al. (2012).

\section{Prior set-up}

To conduct Bayesian inference we have to specify prior distributions for all parameters in the model. Our specific prior set-up follows the penalized spline approach of Scheipl et al. (2012) in implementing the penalized Normal inverse-Gamma prior. This prior set-up is characterized by using a multiplicative parametrization for $\boldsymbol{\beta}_{j}$, motivated by the need to choose specific explanatory variables and to decide whether a co-variate should be modeled in a linear or semi-parametric 
fashion. Specifically, we use a so-called spike-and-slab prior, combined with the Normal-Gamma prior on $\tau_{j}^{2}$. We achieve this by multiplicatively expanding $\boldsymbol{\beta}_{j}=\alpha_{j} \boldsymbol{\zeta}_{j}$, where the scalar $\alpha_{j}$ expresses the importance of the $j$-th co-variate, while the $P_{j} \times 1$ vector $\zeta_{j}$ serves to distribute $\alpha_{j}$ across the parameter block $\boldsymbol{\beta}_{j}$. The prior and hyperparameter structure for $\alpha_{j}$ is as follows:

$$
\begin{aligned}
p\left(\alpha_{j}\right) & \sim \mathcal{N}\left(0, \tau_{j}^{2}\right) \text { with } \tau_{j}^{2}=\gamma_{j} \nu_{j}^{2} \\
p\left(\nu_{j}^{2}\right) & \sim \boldsymbol{\Gamma}^{-1}\left(\underline{a}_{\nu}, \underline{b}_{\nu}\right) \\
p\left(\gamma_{j}\right) & \sim \omega \delta_{1}\left(\gamma_{j}\right)+(1-\omega) \delta_{\kappa_{0}}\left(\gamma_{j}\right) \\
p(\omega) & \sim \mathcal{B}\left(\underline{a}_{\omega}, \underline{b}_{\omega}\right)
\end{aligned}
$$

The prior on the scalar $\alpha_{j}$ in Eq. (10) is motivated by the assumption that $\alpha_{j}$ follows a-priori a Gaussian distribution, with zero mean and variance $\tau_{j}^{2}$. The variance $\tau_{j}^{2}$ is split into two components: $\gamma_{j}$ and $\nu_{j}^{2} \cdot \gamma_{j}$ is a shrinkage indicator variable and $\nu_{j}^{2}$ is the prior variance. We assume an additional level of prior hierarchy and set as the prior for $\nu_{j}^{2}$ an inverse Gamma distribution, with the parameters $\underline{a}_{\nu}$ and $\underline{b}_{\nu}$, and $\underline{a}_{\nu} \ll \underline{b}_{\nu}$ [see Eq. (11)].

$\gamma_{j}$ is assumed to take the value of one with probability $\omega$ and some very small value $\kappa_{0}$ with the probability $1-\omega$. $\delta_{\kappa_{0}}\left(\gamma_{j}\right)$ is zero for any $\gamma_{j} \neq \kappa_{0}$, and is one if $\gamma_{j}=\kappa_{0}$. The prior in Eq. (12) for $\gamma_{j}$ completes the spike and slab prior on $\alpha_{j}$. The implied prior on the variance $\tau_{j}^{2}=\gamma_{j} \nu_{j}^{2}$ has one part of its prior mass concentrated on very small values close to zero - called the spike, with $\gamma_{j}=\kappa_{0}$ - and the other part of the prior mass being more diffuse and centred on larger values - termed as the slab, with $\gamma_{j}=1$. An explanatory variables' posterior coefficient $\gamma_{j}$, that is strongly sampled from the spike prior mass, will be aggressively shrunk towards zero (if $\kappa_{0}$ is set to a sufficiently small value). In this fashion, the posterior probability of $\gamma_{j}=\kappa_{0}$ can be interpreted as the probability of exclusion of $f_{j}(\cdot)$ from the model. The Beta distributed hyperprior on $\omega$ in Eq. (13), with parameters $\underline{a}_{\omega}$ and $\underline{b}_{\omega}$ sets the overall probability of explanatory variables being exor included in the model.

For the spline coefficient vector $\boldsymbol{\zeta}_{j}$, we set a Gaussian prior distribution, shown in Eq. (14), with mean $g_{l_{j}, j}$ and variance of one:

$$
\begin{aligned}
p\left(\boldsymbol{\zeta}_{j} \mid \boldsymbol{g}_{j}\right) & \sim \mathcal{N}\left(\boldsymbol{g}_{j}, \mathbf{I}_{Q}\right) \\
p\left(g_{l_{j}, j}\right) & \sim \frac{1}{2} \delta_{1}\left(g_{l_{j}, j}\right)+\frac{1}{2} \delta_{-1}\left(g_{l_{j}, j}\right) .
\end{aligned}
$$

The mean $g_{l_{j}, j}$ of the Gaussian prior distribution for $\boldsymbol{\zeta}_{j}$ is with equal probability +1 or -1 , as in Eq. (15). This effectively assigns as a prior for $\boldsymbol{\zeta}_{j}$ a mixture of two independently and identically distributed Gaussian mixture distributions with prior mean of \pm 1 . While the mean of $p\left(\boldsymbol{\zeta}_{j}\right)$ is still equal to zero, the bivariate prior assigns most of the prior mass to either positive or negative unity, thereby enabling us to interpret $\alpha_{j}$ as the relative importance of the $j$-th explanatory variable (Scheipl et al., 2012).

The prior structure given by Eq. (10) - Eq. (15) may be termed the penalized Normal mixture inverse-Gamma prior. Note, that for the spike-and-slab part of the prior structure in Eq. (12) and Eq. (13), we used the spike and slab approach from Ishwaran and Rao (2005). An alternative spike and slab prior, which has been suggested for similar models, is the stochastic search variable selection (SSVS) prior by George and McCulloch (1997), as well as the prior specification by Kuo and Mallick (1998), which was recently suggested for use in spatial autoregressive models by Piribauer and Cuaresma (2016).

The key difference of the prior structure of Ishwaran and Rao (2005) compared to the SSVS or the prior structure of Kuo and Mallick (1998) is the use of a continuous Beta distributed prior for the hyperparameter $\omega$ in Eq. (13), compared to the bimodal binomial prior that the SSVS prior uses. This implies that the prior is somewhat easier to specify than in the SSVS case. This is due to the fact that the classic implementation of the SSVS prior requires running a Maximum Likelihood estimate of the model, in order to estimate the variance of the prior distributions. This proves a difficult task in conjunction with splines, since the number of effective co-variates makes Maximum Likelihood estimation often infeasible. The prior set-up by Ishwaran and Rao (2005), is independent of this estimation procedure. While the prior structure suggested by Kuo and Mallick (1998) does not necessitate a previous estimation of the prior parameters, but it still requires 
specifying a seperate $\omega$ for each co-variate, as opposed to the prior structure of Ishwaran and Rao (2005). Additionally, Ishwaran and Rao (2005) provide some desirable analytical properties of a Beta prior for $\omega$, especially if the hyperparameters $\underline{a}_{\omega}$ and $\underline{b}_{\omega}$ are set, so that the distributions is close to uniform.

For the prior on $\boldsymbol{\beta}_{0}$, we follow the canonical Bayesian approach with a Gaussian prior [see Eq. (16)], with $\underline{\boldsymbol{\mu}}_{\beta_{0}}$ vector of prior means and $\underline{\boldsymbol{\Sigma}}_{\beta_{0}}$ as prior variance:

$$
\begin{aligned}
& p\left(\boldsymbol{\beta}_{0}\right) \sim \mathcal{N}\left(\underline{\boldsymbol{\mu}}_{\beta_{0}}, \underline{\boldsymbol{\Sigma}}_{\beta_{0}}\right) \\
& p\left(\sigma^{2}\right) \sim \boldsymbol{\Gamma}^{-\mathbf{1}}\left(\underline{a}_{\sigma^{2}}, \underline{b}_{\sigma^{2}}\right) .
\end{aligned}
$$

The prior for the model variance $\sigma^{2}$ is an inverse-Gamma distribution with parameters $\underline{a}_{\sigma^{2}}$ and $\underline{b}_{\sigma^{2}}$. Finally, for the prior of $\rho$, we follow LeSage and Pace (2009):

$$
p(\rho) \sim \mathcal{U}(-1,1)
$$

and assign a uniform prior in the range of \pm 1 . This concludes our prior set-up.

\section{Conditional posteriors}

The prior structure described in the previous section combined with the full model likelihood gives rise to a set of conditional posteriors from well-known distributions, all available in closed form, which facilitates a Markov Chain Monte Carlo (MCMC) algorithm.

For notational convenience let $\mathbf{Z}=\left[\mathbf{Z}_{1}, \ldots, \mathbf{Z}_{Q}\right]$ denote the full set of design matrices. The full conditional posterior for the multiplicative parameter vector $\boldsymbol{\alpha}=\left(\alpha_{1}, \ldots, \alpha_{Q}\right)^{\prime}$ depends on design matrix $\mathbf{Z}_{\alpha}=\mathbf{Z}$ blockdiag $\left(\boldsymbol{\zeta}_{1}, \ldots, \boldsymbol{\zeta}_{Q}\right)$, conditional on $\boldsymbol{\zeta}=\left(\boldsymbol{\zeta}_{1}^{\prime}, \ldots, \boldsymbol{\zeta}_{Q}^{\prime}\right)$. Analogously, $\mathbf{Z}_{\zeta}$ depends on the design matrix $\mathbf{Z}_{\zeta}=\mathbf{Z} \operatorname{diag}\left(\right.$ blockdiag $\left.\left[\boldsymbol{\iota}_{L_{1} 1}, \ldots, \boldsymbol{\iota}_{L_{Q} Q}\right) \boldsymbol{\alpha}\right]$. Furthermore, let $\mathbf{A}=\left(\mathbf{I}_{N}-\rho \mathbf{W}\right)^{-1}$. by

Under the prior assumption given in Eqs. (10) - (13) the conditional posterior for $\boldsymbol{\alpha}$ is given

$$
\begin{aligned}
p(\boldsymbol{\alpha} \mid \cdot) & \sim \mathcal{N}\left(\boldsymbol{\mu}_{\boldsymbol{\alpha}}, \boldsymbol{\Sigma}_{\boldsymbol{\alpha}}\right) \\
\boldsymbol{\Sigma}_{\boldsymbol{\alpha}} & =\left(\frac{1}{\sigma^{2}} \mathbf{Z}_{\alpha}^{\prime} \mathbf{Z}_{\alpha}+\operatorname{diag}\left(\gamma \boldsymbol{\nu}^{2}\right)^{-1}\right)^{-1} \\
\boldsymbol{\mu}_{\boldsymbol{\alpha}} & =\boldsymbol{\Sigma}_{\boldsymbol{\alpha}}\left(\frac{1}{\sigma^{2}} \mathbf{Z}_{\alpha}^{\prime} \mathbf{A} \boldsymbol{y}_{s p l}\right) .
\end{aligned}
$$

Here, the $N \times 1$ vector $\boldsymbol{y}_{s p l}$ in Eq. (19) corresponds to the response $\boldsymbol{y}$ without the linear trend $\boldsymbol{\eta}_{0}$. The full conditional posterior densities for $\gamma_{j}$ and $\nu_{j}^{2}$ given as:

$$
\begin{aligned}
\frac{p\left(\gamma_{j}=1 \mid \cdot\right)}{p\left(\gamma_{j}=\kappa_{0} \mid \cdot\right)} & =\frac{\omega}{1-\omega} \kappa_{0}^{1 / 2} \exp \left(\frac{1-\kappa_{0}}{2 \kappa_{0}} \frac{\boldsymbol{\alpha}_{j}^{2}}{\nu_{j}^{2}}\right) \\
p\left(\nu_{j}^{2} \mid \cdot\right) & \sim \boldsymbol{\Gamma}^{-1}\left(\underline{a}_{\nu}+\frac{1}{2}, \underline{b}_{\nu}+\frac{\boldsymbol{\alpha}_{j}^{2}}{2 \gamma_{j}}\right) .
\end{aligned}
$$

The posterior for the hyperparamater $\omega$ is given as:

$$
p(\omega \mid \cdot) \sim \mathcal{B}\left(\underline{a}_{\omega}+\sum_{j}^{Q} \delta_{1}\left(\gamma_{j}\right), \underline{b}_{\omega}+\sum_{j}^{Q} \delta_{\kappa_{0}}\left(\gamma_{j}\right)\right)
$$

where $\delta_{1}(\cdot)$ and $\delta_{\kappa_{0}}(\cdot)$ correspond to the Dirac-delta function, with parameter one and $\kappa_{0}$, respectively. Given the priors in Eqs. (14) - (15), the conditional posterior of $\boldsymbol{\zeta}$ is Gaussian and given as:

$$
\begin{aligned}
p(\boldsymbol{\zeta} \mid \cdot) & \sim \mathcal{N}\left(\boldsymbol{\mu}_{\boldsymbol{\zeta}}, \boldsymbol{\Sigma}_{\boldsymbol{\zeta}}\right) \\
\boldsymbol{\Sigma}_{\boldsymbol{\zeta}} & =\left(\frac{1}{\sigma^{2}} \mathbf{Z}_{\zeta}^{\prime} \mathbf{Z}_{\zeta}+\mathbf{I}_{N}\right)^{-1} \\
\boldsymbol{\mu}_{\boldsymbol{\zeta}} & =\boldsymbol{\Sigma}_{\boldsymbol{\zeta}}\left(\frac{1}{\sigma^{2}} \mathbf{Z}_{\zeta}^{\prime} \mathbf{A} \boldsymbol{y}_{l i n}+\boldsymbol{g}\right)
\end{aligned}
$$


where $\boldsymbol{g}=\left[\boldsymbol{g}_{1}^{\prime}, \ldots, \boldsymbol{g}_{j}, \ldots, \boldsymbol{g}_{Q}^{\prime}\right]^{\prime}$ and $\boldsymbol{g}_{j}=\left[g_{1}, \ldots, g_{l_{j}}, \ldots, g_{L_{j}}\right]$. Furthermore, let $\boldsymbol{y}_{\text {lin }}=\boldsymbol{y}-$ $\sum_{j=1}^{Q} \mathbf{Z}_{j} \boldsymbol{\beta}_{j}$. The conditional posterior for $\boldsymbol{g}_{j}$ is:

$$
p\left(\boldsymbol{g}_{j}=1 \mid \cdot\right)=\frac{1}{1+\exp \left(-2 \boldsymbol{\zeta}_{j}\right)} .
$$

The conditional posteriors distributions for $\boldsymbol{\beta}_{0}$ and $\sigma^{2}$ are due to the conjugate nature of their priors a Gaussian and an inverse-Gamma distribution, respectively. They are given in their well-known form as:

$$
\begin{aligned}
p\left(\boldsymbol{\beta}_{0} \mid \cdot\right) & \sim \mathcal{N}\left(\boldsymbol{\mu}_{\boldsymbol{\beta}_{0}}, \boldsymbol{\Sigma}_{\boldsymbol{\beta}_{0}}\right) \\
\boldsymbol{\Sigma}_{\boldsymbol{\beta}_{0}} & =\left(\frac{1}{\sigma^{2}} \mathbf{X}_{0}^{\prime} \mathbf{X}_{0}+\underline{\boldsymbol{\Sigma}}_{\beta_{0}}\right)^{-1} \\
\boldsymbol{\mu}_{\boldsymbol{\beta}_{0}} & =\boldsymbol{\Sigma}_{\boldsymbol{\beta}_{0}}\left(\frac{1}{\sigma^{2}} \mathbf{X}_{0}^{\prime} \boldsymbol{y}+\underline{\boldsymbol{\Sigma}}_{\beta_{0}} \underline{\boldsymbol{\mu}}_{\beta_{0}}\right)
\end{aligned}
$$

and

$$
p\left(\sigma^{2} \mid \cdot\right) \sim \boldsymbol{\Gamma}^{-1}\left(N / 2+\underline{a}_{\sigma^{2}}, \underline{b}_{\sigma^{2}}+\frac{\sum_{i}^{N}\left(y_{i}-\eta_{i}\right)^{2}}{2}\right)
$$

where $\eta_{i}$ is the $i$-th element of the $N \times 1$ vector $\boldsymbol{\eta}=\boldsymbol{\eta}_{0}+\sum_{j=1}^{Q} \mathbf{Z}_{j} \boldsymbol{\beta}_{j}$. Unfortunately the conditional distribution of $\rho$ is of no well-known form and is given by:

$$
p(\rho \mid \cdot) \propto|\mathbf{A}| \exp \left(-\frac{1}{2 \sigma^{2}}(\mathbf{A} \boldsymbol{y}-\boldsymbol{\eta})^{\prime}(\mathbf{A} \boldsymbol{y}-\boldsymbol{\eta})\right) p(\rho) .
$$

This implies that $p(\rho \mid \cdot)$ is not readily available, which prevents the usage of simple Gibbs steps for this parameter. $\rho$ can, however, be sampled via a Metropolis-Hastings step.

\section{Sampling procedure}

With the conditional posteriors for $\boldsymbol{\alpha}, \gamma_{j}, \nu_{j}^{2}, \omega, \boldsymbol{\zeta}, \boldsymbol{g}, \boldsymbol{\beta}_{0}, \sigma^{2}$ and $\rho$ given by Eqs. (19) - (25), respectively, MCMC estimation of the above outlined model involves sequential updating of the model parameters for $T$ steps. We denote the value of the parameter at step $t(t=0, \ldots, T)$ with the superscript $(t)$. Thus, we can write the MCMC algorithm as:

(a) Initialise $\boldsymbol{\gamma}^{(0)}, \boldsymbol{\nu}^{\mathbf{2}^{(0)}}, \omega, \boldsymbol{g}^{(0)}, \boldsymbol{\beta}_{0}^{(0)}, \boldsymbol{\beta}^{(0)}, \sigma^{2(0)}$ and $\rho^{(0)}$ using maximum likelihood estimates or draws from the prior.

(b) Compute $\boldsymbol{\alpha}^{(0)}, \boldsymbol{\zeta}^{(0)}$ and $\mathbf{X}_{\alpha}^{(0)}$.

(c) Obtain a draw for $\boldsymbol{\alpha}^{(t)}$ via the conditional posterior $p\left(\boldsymbol{\alpha}^{(t)} \mid \cdot\right)$ in Eq. (19).

(d) Calculate $\mathbf{Z}_{\zeta}^{(t)}=\mathbf{Z} \operatorname{diag}\left(\right.$ blockdiag $\left.\left[\boldsymbol{\iota}_{l_{1} 1}, \ldots, \iota_{l_{Q} Q}\right] \boldsymbol{\alpha}^{(t)}\right)$.

(e) Sample $\boldsymbol{g}_{j}^{(t)}$ from the posterior $p\left(\boldsymbol{g}_{j}^{(t)} \mid \cdot\right)$, see Eq. (23), for $j=1, \ldots, Q$.

(f) Sample $\boldsymbol{\zeta}^{(t)}$ from the conditional posterior $p\left(\boldsymbol{\zeta}^{(t)} \mid \cdot\right)$, see Eq. (23).

(g) Rescale $\boldsymbol{\zeta}_{j}^{(t)}$ and $\alpha_{j}^{(t)}$ as in Eqs. (26) and (27), for $j=1, \ldots, Q$.

(h) Calculate $\mathbf{Z}_{\alpha}^{(t)}=\mathbf{Z}$ blockdiag $\left(\boldsymbol{\zeta}_{1}^{(t)}, \ldots, \boldsymbol{\zeta}_{Q}^{(t)}\right)$.

(i) Update $\nu_{1}^{2^{(t)}}, \ldots, \nu_{Q}^{2(t)}$ from their conditional posterior in Eq. (21).

(j) Update $\gamma_{1}^{2^{(t)}}, \ldots, \gamma_{Q}^{2}{ }^{(t)}$ from their conditional posterior in Eq. (20). 
(k) Draw $\omega^{(t)}$ from its consitional posterior $p\left(\omega^{(t)} \mid \cdot\right)$ as per Eq. (22).

(l) Update $\boldsymbol{\beta}_{0}^{(t)}$ from their conditional posterior, see Eq. (24).

(m) Update $\sigma^{2^{(t)}}$ from its posterior in Eq. (24).

(n) Finally, use a random walk Metropolis step to sample $\rho^{(t)}$ with the following proposal density: $\mathcal{N}\left(\rho^{(t-1)}, \nu_{\rho}^{2}\right)$, where $\rho^{(t-1)}$ denotes the previous value and $\nu_{\rho}^{2}$ governs the step size.

A fixed number of draws are stored after having discarded the first set of draws as burn-in (see, for example in Koop (2003)).

The rescaling in step $(\mathrm{g})$ is suggested by Scheipl et al. (2012) as an important method to ensure identifiability for $\alpha_{j}$ and $\boldsymbol{\zeta}_{j}$. Without the rescaling, $\alpha_{j}$ and $\boldsymbol{\zeta}_{j}$ are not identifiable and their sampled values can wander to extreme regions of the posterior distribution, without a change in fit. This could for example happen if value of $\alpha_{j}$ are extremely large and sampled values of $\boldsymbol{\zeta}_{j}$ would be extremely slow. To avoid this pitfall, the following rescaling is applied:

$$
\begin{gathered}
\boldsymbol{\zeta}_{j} \rightarrow \frac{L_{j}}{\sum_{l_{j}}^{L_{j}}\left|\zeta_{j l_{j}}\right|} \boldsymbol{\zeta}_{j} \\
\alpha_{j} \rightarrow \frac{\sum_{l_{j}}^{L_{j}}\left|\zeta_{j l_{j}}\right|}{L_{j}} \alpha_{j}
\end{gathered}
$$

The rescaling given by Eq. (26) and (27) ensures that $\alpha_{j}$ is scaled in a way that leaves $\boldsymbol{\beta}_{j}=\alpha_{j} \boldsymbol{\zeta}_{j}$ unchanged, but ensures that $\left|\boldsymbol{\zeta}_{j}\right|$ has mean of one. This completes the description of the Markov Chain Monte Carlo algorithm employed.

\section{$5 \quad$ European freight generation and attraction}

In this section we apply the spatial semi-parametric freight generation and attraction model to a cross-section of 258 regions. Thereby we illustrate the applicability of our approach for unveiling spatial structures, identifying model covariates and nonlinear influences of explanatory variables.

\section{Data and space}

Our data sample consists of cross-sectional observations on 258 European regions comprising 25 countries over the period of 2010-2014. Our unit of observation is the NUTS-2 level region, as defined by the 2010 revision of the European Commission. Although these regions correspond to administrative boundaries, they are frequently used in regional economics to model the subnational variations prevalent in countries. Our sample consists of regions located in Austria (nine regions), Belgium (11 regions), Bulgaria (six regions), Czech Republic (eight regions), Germany (38 regions), Denmark (five regions), Estonia (one region), Greece (13 regions), Spain (15 regions), Finland (four regions), France (22 regions), Hungary (seven regions), Ireland (two regions), Italy (21 regions), Latvia (one region), Luxembourg (one region), Lithuania (one region), the Netherlands (12 regions), Poland (16 regions), Portugal (five regions), Romania (eight regions), Sweden (eight regions), Slovenia (two regions), Slovakia (four regions) and the United Kingdom (37 regions). For a complete list of the NUTS-2 regions included in this study, refer to Table B1 in Appendix B. This contains all EU-27 countries except Cyprus and Malta. The latter two have been excluded from the analysis due to the lack of available freight data from Eurostat.

Our dependent variables are the average total freight - measured in ten million tons - generated and attracted by NUTS-2 regions in the period of 2010 to 2014. The total generated and attracted freight was calculated as the sum of road, rail, inland waterways, maritime and air freight goods being loaded and unloaded in the study regions. All data tables on the amount of freight loaded and unloaded stem from the European Comission's (2016) Eurostat database. Fig. 1 shows on a map the NUTS-2 regions included in the study and the average amount of yearly generated and attracted freight.

[Fig. 1 about here.] 
We consider a set of $K=20$ explanatory variables, as well as their spatially lagged variants. In order to avoid potential problems with endogeneity, all explanatory variables are observed in 2006. Table 1 contains a list of the explanatory variables in the study, a detailed description of each variable, as well as an overview of their respective data sources.

Almost all freight generation and attraction studies include a variable measuring per capita income. We include regional domestic product per capita measured in millions of Euro in both of our models. In the freight generation model it serves as a measure for regional productivity, while in the freight attraction model it proxies regional per capita demand. Following Celik and Guldmann (2007), we also include the gross value added contribution of the manufacturing sector. They argue that this is a significant measure for the relative sectoral competitiveness of regions.

Furthermore, employment either in total, or differentiated by specific sectors, plays a significant role, both in explaining freight generation and freight attraction. In the case of freight generation, employment is an indication of the relative strength of a particular industry, and especially the manufacturing sector should emerge as a main driver of freight generation. In the case of freight attraction, sectoral employment in manufacturing and construction can be seen as a proxy for the demand for intermediate goods. Motivated by this, we include the share of employment in the manufacturing, construction and market services sectors in our analysis. Based on Novak et al. (2008), Chow et al. (2010) and Sánchez-Díaz et al. (2016) we expect the share of employment in manufacturing to be strongly significant. Novak et al. (2008) test different functional forms of sectoral employment and find strong support for quadratic influences.

We include further sectoral information in the form of the gross value contribution of regions' manufacturing. This sectoral indicator is expected to be strongly significant, as evidence presented by Chow et al. (2010) indicates that in both freight generation and attraction the manufacturing sector plays a central role. Furthermore, in the spirit of Chun et al. (2012) we include the average productivity of manufacturing companies, measured by the ratio of sectoral gross value added and the number of local units in the region. This aggregate explanatory variable serves as a measure for manufacturing competitiveness. Theory indicates that more competitive regions would generate and attract a greater volume of freight.

The characteristics of regional population play an important role in both freight attraction (Chun et al., 2012) and freight generation (Celik and Guldmann, 2007). In the case of freight attraction population density can be seen as a measure of consumer demand, in the case of freight generation, it is interpreted as a measure for urban and industrial concentration. Ranaiefar et al. (2013) find considerable evidence for the nonlinear influence of population density on freight attraction as well. Therefore, we follow Chow et al. (2010) and include population density as an explanatory variable in both models. As additional indication of a regions' population - especially to indicate the structure of urban centres - we add a set of dummy variables: namely, variables indicating whether a region contains a national capital, and major cities, and whether a region is predominantly rural. The findings on the influence of capital city regions are varied in literature. While a high population density seems to attract and generate a greater volume of freight, this does not seem to be true for major cities. Usually the largest factories and manufacturing centres are located at the outskirts of cities, therefore possible spatial spillovers might occur.

Multiple recent publications (Celik and Guldmann, 2007; Novak et al., 2008; Tavasszy et al., 2012; Wagner, 2010) emphasize the importance of logistics related factors for freight attraction and generation. In order to proxy these potential effects of logistics, we include the share of companies and the share of employment in land transport and pipelines, together with the warehousing activities per region. Moreover, we measure the number of commercial maritime ports and the number of commercial airports per region, as a proxy for transportation infrastructure, in combination with the length of the road network and the closest travel time to maritime ports. Almost all studies show the importance of transport infrastructure for freight generation and attraction.

[Table 1 about here.]

Moreover, we follow Lawson et al. (2012), Sánchez-Díaz et al. (2016) and Chow et al. (2010), and include urbanization - the share of urban areas per the population density of the region - as a measure of land-use activities. Higher urbanization typically indicates a higher rate of manufacturing and production activities and larger demand markets. 
Finally, we have included some indicators of our own; by measuring the effects of national borders, whether a region has received Objective 1 funding in the period 2000 to 2006, and whether a region has a sea coast (see Table 1). Table B2 in Appendix B contains summary statistics of the dependent and independent variables used in the study.

For constructing the spatial neighborhood matrix we use the geodesic distance between the centroids of NUTS-2 regions included in our analysis. We tested model specification containing a spatial neighborhood matrix with five to twelve nearest neighbors. The results did not change significantly. The current results all stem from a model with a spatial weight matrix with a seven nearest neighbor specification. We used Moran's $I$ as a measure of spatial correlation prevalent in the data. The test yielded a Moran's $I$ value of $0,1596(p<0.001)$ for freight generation and $0,1417(p<0.001)$ in the case of freight attraction.

\section{Prior elicitation and computational notes}

For both the freight generation and attraction models we use the same prior set-up. For the priors of the Normal inverse-Gamma hyperprior structure we set the overall prior inclusion probability of variables as $\underline{a}_{\omega}=1$ and $\underline{b}_{\omega}=1$. This is the most agnostic set-up, since a priori all semiparametric model components have an inclusion probability of 0.5 , and it corresponds to a uniform prior for $\omega$. For the prior variance of $\alpha_{j}$, we set $\underline{a}_{\nu}=1$ and $\underline{b}_{\nu}=25$, which is a rather non-informative setting for the prior variances. The shrinkage parameter is set to $\kappa_{0}=10^{-6}$.

For the parametric part of our model, we again try to be as noninformative as possible in our selection of priors. Therefore, we set the prior for the overall model variance as $\underline{a}_{\sigma^{2}}=0.001$ and $\underline{b}_{\sigma^{2}}=0.001$. Only the intercept is included in $\mathbf{X}_{0}$, thus $K_{0}=1$. For the prior mean and prior variance of the intercept we use diffuse distributions, setting the prior mean to zero and $\underline{\boldsymbol{\Sigma}}_{\mu_{0}}=10^{4} \mathbf{I}_{K_{0}}$.

We set the number of spline knots as $L_{m}=20$. The position of spline knots is equally spaced along along the range of each covariate. Over these spline knots we construct cubic splines, with a first order penalization matrix. Cubic splines should adequately approximate potential nonlinearities and setting a penalization matrix of the first degree mean that the unpenalized part directly corresponds to the linear coefficient vector, which lies in the nullspace of the penalization matrix.

\section{Estimation results}

Posterior inference is based on 20,000 draws with the first 10,000 discarded as burn-ins. ${ }^{4}$ Table 2 and Table 3 report the results of the analysis for the freight generation and attraction models, respectively. The rows in both tables correspond to all $K=24$ explanatory variables and their spatially lagged variants. Column (a) contains the posterior inclusion probability of the unpenalized variable components. An inclusion probability of one corresponds to the variable being included in all the sampled models and an inclusion probability of zero indicates that the variable was excluded from all sampled models. Columns (b) to (e) contain the posterior mean, posterior standard deviation and posterior sign certainty of the unpenalized regression coefficients $\beta_{j}$. Column (e) contains the posterior inclusion probability of the penalized model components, that is the posterior probability $\gamma_{j}=1$ for each of the covariates modeled in a semi-parametric fashion. If the unpenalized posterior inclusion probability of a variable [in column (a)] is close to one and the penalized posterior inclusion probability [column (e)] is close to zero, this can be interpreted as the variable having a predominantly linear impact. If the penalized inclusion probability is close to one, but the penalized part is close to zero, this means that the mean impact of the covariate on the dependent variable is zero, but some nonlinear influences are prevalent. If both the inclusion probability in column (a) and column (e) display an inclusion probability close to one, this can be interpreted as the variable having a strongly nonlinear influence on freight generation or attraction.

Finally, column (f) in Table 2 and Table 3 contains a graphical representation the posterior functional forms of the penalized regression coefficients. This column can be interpreted similarly to its mean, standard deviation and sign probability counterparts in columns (b) - (e) and is

\footnotetext{
${ }^{4}$ We assessed the convergence of our sampler using the diagnostic suggested by Geweke (1992) and implemented in the R-package coda. The obtained $z$-scores of 0.84 and 0.88 for freight generation and attraction, respectively, suggest a successful convergence of the sampler.
} 
used as a practical method of summarizing 20 regression coefficients corresponding to $\boldsymbol{\beta}_{j}$. Each graphic shows the posterior impact of $f_{j}(\cdot)$ on $\boldsymbol{y}$ in the interval \pm 1 . The shaded areas confer to $80 \%$ confidence intervals and the continuous black line corresponds to the zero-line. It is readily observable that all functions with a penalized posterior inclusion probability [column (e)] close to zero are strongly shrunk to a straight line at $\boldsymbol{y}=0$, while function with inclusion probability close to one display significant nonlinear influence of the $j$-th co-variate.

[Table 2 about here.]

The posterior inclusion probabilities of the co-variates in the freight generation model are presented in Table 2. The posterior inclusion probabilities of the explanatory variables display a similar pattern to the freight attraction model in Table 3, with small differences in the specific coefficient estimates. Both Manufacturing gross value added and its spatially lagged counterpart have posterior inclusion probability of unity, that is they have been included in all posterior models. Only the non-spatially lagged semi-parametric model term of Manufacturing gross value added exhibits a posterior inclusion probability of close to unity. Moreover, the penalized model term of $\boldsymbol{W}$ Population density exhibits a high inclusion probability, close to one, while its linear version is excluded from the majority of the posterior models $\left(\gamma_{j}=0.0537\right)$. A region being a capital city seems to play a central role in the majority of the models $\left(\gamma_{j}=0.9825\right)$ with a sign probability of unity towards a negative impact. The spatial coefficient $\rho$ is highly significant with $\rho=0.4274$ (s.d. 0.0670).

\section{[Table 3 about here.]}

Turning our attention to the posterior inclusion probabilities in the freight attraction model (Table 3), we can see that the spatial parameter $\rho$ is significant at 0.2485 (s.d. 0.0996) and positive, which indicates the presence of positive spatial spillovers. This is inline with earlier findings by Novak et al. (2008), who also found strongly significant and positive spatial autocorrelation. Furthermore, we observe that the Manufacturing gross value added and its spatially lagged counterpart exhibit an inclusion probability close to one. This is in-line with similar findings from Chow et al. (2010), where the intermediate demand markets (proxied by the gross value added in manufacturing activities) play the central role in attracting the majority freight, as opposed to consumer demand markets. The differing signs for the coefficient Manufacturing gross value added and its spatially lagged counterpart indicate some support for Ranaiefar et al. (2013), where logistical activity is strong on regions neighboring manufacturing sites. Moreover, the penalized component of Manufacturing gross value added also has a high posterior inclusion probability. The functional form in column (f) indicates that higher values of Manufacturing gross value added have a proportionally stronger impact on attracting freight than lower values.

While in their unpenalized form the coefficients corresponding to Population density and its spatially lagged counterpart do not exhibit posterior inclusion probabilities above 0.9, the penalized model component corresponding to $\boldsymbol{W}$ Population density is included in all posterior models. The functional form depicted in column (f) indicate that population density up to 1,000 inhabitants per square $\mathrm{km}$ has a comparatively negative effect, while population density in the ranges from 1,000 inhabitants to 1,600 inhabitants to square $\mathrm{km}$ seem to have a comparatively positive effects on freight attraction. The covariate Capital city region also exhibits a posterior inclusion probability close to one.

\section{[Table 4 about here.]}

For the purposes of comparing the impact of spatial dependence on the model, we ran corresponding freight generation and attraction models without spatial dependence, that is $\rho=0$. The results are displayed in Table $4 .^{5}$ The residuals of the freight generation and attraction models both display significant spatial dependence, with a Moran's I of 0.142 and 0.141 (and both with $p_{\mathbf{i}} 0.001$ ),

\footnotetext{
${ }^{5}$ Our posterior inference is based again on 20,000 draws, with the first 10,000 discarded as burn-ins. Results obrained from the convergence diagnostics of Geweke (1992), as implemented in the R-package coda, suggest a successful convergence of the sampler, with test values of 0.86 and 0.91 for freight generation and attraction, respectively.
} 
respectively. We compare both models to their spatially lagged counterparts using Bayes factor and a non-informative prior (see Koop 2003). In both cases the test favours the model containing the spatial lags. The resulting parameter estimates also show considerable bias, both in the freight generation and attraction models. As a further point of comparison, Table B3 in Appendix B presents the estimated results from a non-semi-parametric spatial Durbin model. The model was run using the MCMC sampler presented in LeSage and Pace (2009), Chapter 5, Section 3.

Figure 2 displays the functional fit for the two penalized model terms with the highest posterior inclusion probability, for the freight generation and freight attraction model, respectively. The posterior mean functional form of Manufacturing gross value added exhibits initially low impacts in the range of $0.01-0.068$, both in the freight attraction and generation models - see panels (i) and (iv). In the range of 1.11 - 1.32 the posterior mean of Manufacturing gross value added shows comparatively higher positive impacts on freight attraction and generation, respectively. This indicate that the impact of Manufacturing gross value added does not continuously remain the same over its range of values, but increases sharply.

The functional form of the penalized counterpart of the model term $\boldsymbol{W}$ Population density in panels (ii) and (iii) exhibits a positive spike at 1.34 and 1.37, respectively. Otherwise, it is negative or not significantly different from zero. This indicates that a region with a population density of $1.340-1.370$ inhabitants per square $\mathrm{km}$ is much more likely to generate or attract freight. This is in all likelihood a proxy effect for industrial and/or warehousing regions, which share a specific pattern of population density.

[Fig. 2 about here.]

Table 5 shows the posterior spatial impact estimates of both the freight generation - displayed in panel (a) - and freight attraction model - shown in panel (b). The first three columns correspond to the posterior mean, standard deviation and sign probability of the average direct impacts, respectively. Columns 4-6 display the corresponding values for the indirect impacts and columns 7-9 show the posterior total impact coefficients.

In both models Manufacturing gross value added has a sign probability of close to unity and is positive. According to these results, if in a region the gross value added contribution of the manufacturing sector increases by one million Euro then, freight generation in that region will increase by 2.2 million tons (std. dev. 0.519) and freight attraction by 1.9 million (std. dev. 0.485). Conversely, an average increase in the gross value added contribution of the manufacturing sector by one million euro in a regions' neighbors, should increase freight attraction by 1.7 million tons (std. dev. 0.465) and freight generation by 1.4 million (std. dev. 0.405). If a region is a capital city, this decreases its freight generation in comparison to non-capital city regions by -0.49 million tons and freight attraction by -0.48 million tons. In regions neighboring capital cities, freight attraction is decreased by -0.36 million tons and freight generation by -0.35 million tons, on average.

\section{[Table 5 about here.]}

In conclusion we note that our approach allowed us to provide estimates and inference, regarding which variables out of a set of 20 contribute significantly to freight generation and attraction. Moreover, we could infer that the manufacturing sector seems to have a nonlinear in the parameters impact on both freight generation and attraction and we could provide an estimate of the functional form. Furthermore, spatial spillovers are significant in both models at the values 0.427 and 0.248 , respectively.

\section{Closing remarks}

The classic regional freight generation and attraction models suffer from a series of weaknesses. First, they do not take spatial lags of the explanatory or dependent variables into account, thus leading to biased and inconsistent estimates (Novak et al., 2008). Second, there is no clear consensus as to the choice of explanatory variables in the models (Chow et al., 2010). The classical model emphasizes gross regional product, population density and indicators of sectoral performance, 
several authors argue for land-use indicators (Boerkamps et al. 2000, Chow et al. 2010, Wagner 2010 and Wisetjindawat et al. 2006) or indicators of regional logistic and warehousing activities (Hesse and Rodrigue 2004, Tavasszy et al. 2012). Third, there is considerable evidence for nonlinearity in the models, however, there is no clear consensus on the functional form of this nonlinearity (Rodrigue 2006, Hesse and Rodrigue 2004 and Ranaiefar et al. 2013).

Novak et al. (2008) provide evidence for siginficant spatial spillovers in both freight attraction and freight generation. Based on semi-parametric methods and in the spirit of Scheipl et al. (2012), we use an approach based on penalized basic splines to approximate possible nonlinearities. Moreover, we implement Bayesian variable selection through a penalized Normal inverse-Gamma prior structure, which enables us to make inference over the coefficients with the highest posterior inclusion probability. Furthermore, this prior structure, coupled with the penalized spline representation, enables inference over the nonlinear influence of variables.

In the context of European freight generation, we find considerable influence for spatial dependencies among both the freight generation and attraction of NUTS-2 level regions. Furthermore, we provide evidence that the manufacturing sector seems to play a key role in European freight generation, with an increase in the gross value added resulting in a significant increase in freight generation. Finally, we show that both the gross value added of the manufacturing sector, as well as the population of neighbouring regions exhibit a nonlinear influence on freight generation and attraction. This provides a clear evidence for the nonlinearities stemming from logistical and transportation related factors, as advocated by Rodrigue (2006) and Ranaiefar et al. (2013).

\section{References}

Anselin L (1988) Spatial Econometrics: Methods and Models. Kluwer Academic, Dordrecht

Anselin L and Bera A (1998) Spatial dependence in linear regression models with an introduction to spatial econometrics. In Ullah A and Giles DEA, eds., Handbook of Applied Economic Statistics. Marcel Dekker, New York, 237-289

Arbia G (2006) Spatial Econometrics: Statistical Foundations and Applications to Regional Convergence. Springer Science \& Business, Berlin Heidelberg New York

Basile R (2008) Regional economic growth in Europe: A semiparametric spatial dependence approach. Papers in Regional Science 87(4), 527-544

Basile R, Mínguez R, Montero JM and Mur J (2014) Modelling regional economic dynamics: Spatial dependence, spatial heterogeneity and nonlinearities. Journal of Economic Dynamics and Control 48(1), 229-245

Boerkamps J, Binsbergen AV and Bovy P (2000) Modeling behavioral aspects of urban freight movement in supply chains. Transportation Research Record: Journal of the Transportation Research Board 1725(1), 1-11

Brezger A and Lang S (2006) Generalized structured additive regression based on Bayesian Psplines. Computational Statistics 85 Data Analysis 50(4), 967-991

Celik MH and Guldmann JM (2007) Spatial interaction modeling of interregional commodity flows. Socio-Economic Planning Sciences 41(2), 147-162

Chow JYJ, Yang CH and Regan AC (2010) State-of-the art of freight forecast modeling: Lessons learned and the road ahead. Transportation 37(6), 1011-1030

Chun Y, Kim H and Kim C (2012) Modeling interregional commodity flows with incorporating network autocorrelation in spatial interaction models: An application of the US interstate commodity flows. Computers, Environment and Urban Systems 36(6), 583-591 
De Grange L, Boyce D, González F and Ortúzar JDD (2013) Integration of spatial correlation into a combined travel model with hierarchical levels. Spatial Economic Analysis 8(1), 71-91

De Grange L, Fernández E and De Cea J (2010) A consolidated model of trip distribution. Transportation Research Part E: Logistics and Transportation Review 46(1), 61-75

De Jong G, Vierth I, Tavasszy L and Ben-Akiva M (2013) Recent developments in national and international freight transport models within Europe. Transportation 40(2), 347-371

DeBoor C (1978) A Practical Guide to Splines. Springer, Berlin Heidelberg New York

Del Bo CF and Florio M (2012) Infrastructure and growth in a spatial framework: Evidence from the EU regions. European Planning Studies 20(8), 1393-1414

Eilers PHC and Marx BD (1996) Flexible smoothing with B-splines and penalties. Statistical Science 11(2), 89-121

Fahrmeir L, Kneib T and Lang S (2004) Penalized structured additive regression for space-time data: A Bayesian perspective. Statistica Sinica 14(3), 715-745

Fischer MM and Wang J (2011) Spatial Data Analysis: Models, Methods and Techniques. Springer, Heidelberg Dordrecht London New York

Fotopoulos G (2012) Nonlinearities in regional economic growth and convergence: The role of entrepreneurship in the European union regions. Annals of Regional Science 48(3), 719-741

George EI and McCulloch RE (1993) Variable selection via Gibbs sampling. Journal of the American Statistical Association 88(423), 881-889

George EI and McCulloch RE (1997) Approaches for Bayesian variable selection. Statistica Sinica $7(2), 339-373$

Geweke J (1992) Evaluating the accuracy of sampling-based approaches to the calculation of posterior moments. In Bernardo JM, Berger JO, Dawid AP and Smith AFM, eds., Bayesian Statistics. Oxford University Press, Oxford, 4. edition, 167-193

Hesse M and Rodrigue JP (2004) The transport geography of logistics and freight distribution. Journal of Transport Geography 12(3), 171-184

Ishwaran H and Rao JS (2005) Spike and slab variable selection: Frequentist and Bayesian strategies. Annals of Statistics 33(2), 730-773

Koop G (2003) Bayesian Econometrics. John Wiley \& Sons Ltd., West Sussex

Koop G and Poirier D (2004) Bayesian variants of some classical semiparametric regression techniques. Journal of Econometrics 123(2), 259-282

Kuo L and Mallick B (1998) Variable selection for regression models. Sankhya: The Indian Journal of Statistics 60(1), 65-81

Lang S and Brezger A (2004) Bayesian P-Splines. Journal of Computational and Graphical Statistics 13(1), 183-212

Lawson C, Holguín-Veras J, Sánchez-Díaz I, Jaller M, Campbell S and Powers E (2012) Estimated generation of freight trips based on land use. Transportation Research Record: Journal of the Transportation Research Board 2269(1), 65-72

Lesage JP and Fischer MM (2009) Spatial growth regressions: Model specification, estimation and interpretation. Spatial Economic Analysis 3(3), 275-304

LeSage JP and Parent O (2007) Bayesian model averaging for spatial econometric models. Geographic Analysis 39(3), 241-267 
LeSage PJ and Pace RK (2009) Introduction to Spatial Econometrics. CRC Press, Boca Raton London New York

Novak DC, Hodgdon C, Guo F and Aultman-Hall L (2008) Nationwide freight generation models: A spatial regression approach. Networks and Spatial Economics 11(1), 23-41

Ortúzar JdD and Willumsen LG (2011) Modelling Transport. John Wiley \& Sons, Chichester, 4th edition

Piribauer P and Cuaresma JC (2016) Bayesian variable selection in spatial autoregressive models. Spatial Economic Analysis

Piribauer P and Fischer MM (2015) Model uncertainty in matrix exponential spatial growth regression models. Geographical Analysis 47(3), 240-261

Ranaiefar F, Chow JYJ, Rodriguez-Roman D, Veiga de Camargo P and Ritchie SG (2013) Geographic scalability and supply chain elasticity of a structural commodity generation model using public data. Technical report, Institute of Transportation Studies, University of California

Rodrigue JP (2006) Challenging the derived transport-demand thesis: Geographical issues in freight distribution. Environment and Planning A 38(8), 1449-1462

Ruppert D, Wand MP and Carroll RJ (2003) Semiparametric Regression. Cambridge University Press, Cambridge

Sánchez-Díaz I, Holguín-Veras J and Wang X (2016) An exploratory analysis of spatial effects on freight trip attraction. Transportation 43(1), 177-196

Scheipl F, Fahrmeir L and Kneib T (2012) Spike-and-slab priors for function selection in structured additive regression models. Journal of the American Statistical Association 107(500), 1518-1532

Tavasszy LA, Ruijgrok K and Davydenko I (2012) Incorporating logistics in freight transport demand models: State-of-the-art and research opportunities. Transport Reviews 32(2), 203-219

Wagner T (2010) Regional traffic impacts of logistics-related land use. Transport Policy 17(4), $224-229$

Wisetjindawat W and Sano K (2003) A behavioral modeling in micro-simulation for urban freight transportation. Journal of the Eastern Asia Society for Transportation Studies 5(3), 2193-2208

Wisetjindawat W, Sano K and Matsumoto S (2006) Commodity distribution model incorporating spatial interactions for urban freight movement. Transportation Research Record: Journal of the Transportation Research Board 1966(1), 41-50 
Table 1: Variables used in the analysis

\begin{tabular}{|c|c|}
\hline Variable & Description \\
\hline Freight generated & $\begin{array}{l}\text { Annual road, marine, inland waterway, rail and air freight transport by region of } \\
\text { loading (average 2011-2014); measured in ten million tons. (Source: Eurostat) }\end{array}$ \\
\hline Freight attracted & $\begin{array}{l}\text { Annual road, marine, inland waterway, rail and air freight transport by region of } \\
\text { unloading (average 2011-2014); measured in ten million tons. (Source: Eurostat) }\end{array}$ \\
\hline Regional domestic product per capita & $\begin{array}{l}\text { Regional domestic product per inhabitant, in 100,000 Euro, } 2006 . \\
\text { (Source: Eurostat) }\end{array}$ \\
\hline Manufacturing gross value added & $\begin{array}{l}\text { Gross value added of NACE rev } 2 \text { C to I (manufacturing) in billions of Euro, } 2006 . \\
\text { (Source: Eurostat) }\end{array}$ \\
\hline Population density & Share of 1.000 inhabitants per square $\mathrm{km}, 2006$. (Source: Eurostat) \\
\hline Manufacturing employment & $\begin{array}{l}\text { Share of NACE rev } 2 \mathrm{C} \text { to I (manufacturing) in total employment, } 2006 . \\
\text { (Source: Eurostat) }\end{array}$ \\
\hline Construction employment & Share of NACE rev $2 \mathrm{~F}$ (construction) in total employment, 2006. \\
\hline Market services employment & $\begin{array}{l}\text { Share of NACE rev } 2 \text { G to K (market services) in total employment, } 2006 . \\
\text { (Source: Eurostat) }\end{array}$ \\
\hline Avg. production of manufacturing units & $\begin{array}{l}\text { Gross value added per average number of employees of NACE rev } 2 \text { B to } \mathrm{E} \\
\text { (manufacturing) companies, in EUR, 2006. (Source: Eurostat) }\end{array}$ \\
\hline Degree of urbanization & Share of urban surfaces (CLC 11) per population density, 2006. (Source: Eurostat) \\
\hline Share of logistic companies & $\begin{array}{l}\text { Share of local units of NACE rev } 2 \text { sectors H49 ( Land transport and transport via } \\
\text { pipelines) and H52 (Warehousing and support activities for transportation) from } \\
\text { total local companies, 2006. (Source: Eurostat) }\end{array}$ \\
\hline Logistic employment (share) & $\begin{array}{l}\text { Share of employees in NACE rev } 2 \text { sectors } \mathrm{H} 49 \text { (Land transport and transport via } \\
\text { pipelines) and H52 (Warehousing and support activities for transportation), } 2006 . \\
\text { (Source: Eurostat) }\end{array}$ \\
\hline Number of airports & $\begin{array}{l}\text { Number of commercial airports open to all flights in the region, } 2006 . \\
\text { (Source: Eurostat) }\end{array}$ \\
\hline Length of road network $(\mathrm{km})$ & Length of road network in $10,000 \mathrm{~km}, 2001$ (Source: ESPON) \\
\hline Number of seaports & Number of major commercial maritime ports in the region, 2001. (Source: Eurostat) \\
\hline Travel time to seaport (min) & $\begin{array}{l}\text { Car travel time in minutes from region's centroid to the closest major maritime } \\
\text { port, 2001. (Source: Eurostat) }\end{array}$ \\
\hline Capital city region & $\begin{array}{l}\text { Dummy variable; } 1 \text { denotes the presence of a national capital in the region, } \\
0 \text { otherwise (Source: } E S P O N \text { ) }\end{array}$ \\
\hline Region with large city & $\begin{array}{l}\text { Dummy variable; } 1 \text { denotes the presence of a city (inhabitants }>100,000 \text { ) in the } \\
\text { region, } 0 \text { otherwise (Source: Eurostat) }\end{array}$ \\
\hline Rural region & $\begin{array}{l}\text { Dummy variable; } 1 \text { denotes a region with population density below } 100 \text { and } \\
\text { containing no city with more than } 125,000 \text { inhabitants (Source: ESPON) }\end{array}$ \\
\hline Border region & $\begin{array}{l}\text { Dummy variable; } 1 \text { denotes a region with a national border, } 0 \text { otherwise } \\
\text { (Source: Eurostat) }\end{array}$ \\
\hline Objective 1 region & $\begin{array}{l}\text { Dummy variable; } 1 \text { indicates that the region was eligible to apply for Objective } 1 \\
\text { funding in } 2000-2006,0 \text { otherwise. (Source: } E S P O N \text { ) }\end{array}$ \\
\hline Coastal region & $\begin{array}{l}\text { Dummy variable; } 1 \text { denotes that the region has a marine coast, } 0 \text { otherwise } \\
\text { (Source: } E S P O N \text { ) }\end{array}$ \\
\hline
\end{tabular}


Table 2: Freight generation model posterior estimates

\begin{tabular}{|c|c|c|c|c|c|c|}
\hline \multirow[b]{2}{*}{ Variable } & \multicolumn{4}{|c|}{ Unpenalized model part } & \multicolumn{2}{|c|}{ Penalized model part } \\
\hline & $\begin{array}{c}\text { Inclusion } \\
\text { prob. } \\
\text { (a) }\end{array}$ & $\begin{array}{c}\text { Mean } \\
\text { (b) }\end{array}$ & $\begin{array}{l}\text { Std. dev. } \\
\text { (c) }\end{array}$ & $\begin{array}{l}\text { Sign prob. } \\
\text { (d) }\end{array}$ & $\begin{array}{c}\text { Inclusion } \\
\text { prob. } \\
\text { (e) }\end{array}$ & $\begin{array}{l}\text { functional } \\
\text { form } \\
\text { (f) }\end{array}$ \\
\hline $\begin{array}{l}\rho \\
\sigma^{2}\end{array}$ & & $\begin{array}{l}0.4274 \\
0.1455\end{array}$ & $\begin{array}{l}0.0670 \\
0.0311\end{array}$ & 1.0000 & & \\
\hline Regional domestic product per capita & 0.0342 & 0.0070 & 0.0612 & 0.5217 & 0.0812 & \\
\hline W Regional domestic product per capita & 0.0223 & 0.0043 & 0.0412 & 0.5221 & 0.0384 & \\
\hline Manufacturing gross value added & 1.0000 & -2.6829 & 0.3251 & 1.0000 & 0.9284 & \\
\hline W Manufacturing gross value added & 1.0000 & 1.0762 & 0.2716 & 0.9998 & 0.0104 & \\
\hline Population density & 0.0836 & 0.0272 & 0.1023 & 0.5500 & 0.0206 & \\
\hline W Population density & 0.0537 & 0.0379 & 0.2366 & 0.5158 & 0.9946 & $\underline{\underline{Z}}$ \\
\hline Manufacturing employment & 0.0147 & 0.0003 & 0.0246 & 0.5013 & 0.0146 & \\
\hline W Manufacturing employment & 0.0225 & 0.0015 & 0.0316 & 0.5102 & 0.0087 & \\
\hline Construction employment & 0.0171 & 0.0004 & 0.0309 & 0.5074 & 0.0159 & \\
\hline W Construction employment & 0.0329 & -0.0021 & 0.0465 & 0.5040 & 0.0103 & \\
\hline Market services employment & 0.0619 & -0.0150 & 0.0777 & 0.5267 & 0.0050 & \\
\hline W Market services employment & 0.0118 & -0.0004 & 0.0219 & 0.5107 & 0.0108 & \\
\hline Avg. production of manufacturing units & 0.0254 & -0.0036 & 0.0433 & 0.5107 & 0.5883 & \\
\hline W Avg. production of manufacturing units & 0.0196 & -0.0014 & 0.0289 & 0.5065 & 0.0972 & \\
\hline Degree of urbanization & 0.0194 & -0.0008 & 0.0173 & 0.5072 & 0.0165 & \\
\hline W Degree of urbanization & 0.0136 & -0.0027 & 0.0268 & 0.5201 & 0.0101 & \\
\hline Share of logistic companies & 0.0238 & -0.0034 & 0.0528 & 0.5084 & 0.1485 & \\
\hline W Share of logistic companies & 0.0424 & -0.0135 & 0.0797 & 0.5372 & 0.0225 & \\
\hline Logistic employment (share) & 0.0412 & -0.0129 & 0.0770 & 0.5189 & 0.0393 & \\
\hline W Logistic employment (share) & 0.0193 & -0.0022 & 0.0382 & 0.5144 & 0.0280 & \\
\hline Number of airports & 0.1370 & -0.0687 & 0.1981 & 0.5756 & 0.0175 & \\
\hline W Number of airports & 0.0247 & -0.0029 & 0.0358 & 0.5179 & 0.0112 & \\
\hline Length of road network $(\mathrm{km})$ & 0.0381 & -0.0101 & 0.0629 & 0.5232 & 0.0627 & \\
\hline W Length of road network $(\mathrm{km})$ & 0.0192 & 0.0004 & 0.0266 & 0.5067 & 0.0595 & \\
\hline Number of seaports & 0.0124 & -0.0005 & 0.0210 & 0.5049 & 0.0133 & \\
\hline W Number of seaports & 0.0278 & 0.0052 & 0.0473 & 0.5136 & 0.0119 & \\
\hline Travel time to seaport (min) & 0.0122 & -0.0004 & 0.0172 & 0.5025 & 0.0040 & \\
\hline $\mathbf{W}$ Travel time to seaport (min) & 0.0563 & -0.0267 & 0.1199 & 0.5474 & 0.0536 & \\
\hline Capital city region & 0.9825 & -0.3447 & 0.0755 & 1.0000 & & \\
\hline W Capital city region & 0.0159 & -0.0023 & 0.0253 & 0.5175 & & \\
\hline Region with large city & 0.0334 & 0.0073 & 0.0299 & 0.5748 & & \\
\hline W Region with large city & 0.0533 & 0.0161 & 0.0688 & 0.5498 & & \\
\hline Rural region & 0.0136 & -0.0020 & 0.0129 & 0.5358 & & \\
\hline W Rural region & 0.0206 & 0.0019 & 0.0214 & 0.5218 & & \\
\hline Border region & 0.0284 & 0.0059 & 0.0240 & 0.5670 & & \\
\hline W Border region & 0.1965 & 0.0568 & 0.1115 & 0.6547 & & \\
\hline Objective 1 region & 0.0091 & 0.0025 & 0.0145 & 0.5369 & & \\
\hline W Objective 1 region & 0.1251 & 0.0352 & 0.0844 & 0.6209 & & \\
\hline Coastal region & 0.0066 & 0.0001 & 0.0095 & 0.5008 & & \\
\hline W Coastal region & 0.0300 & -0.0078 & 0.0392 & 0.5512 & & \\
\hline
\end{tabular}

Notes: Posterior results based on $\mathbf{W}$ matrix with seven nearest neighbors. The plots in column (f) are all bounded on the $y$-axis at \pm 1 . The shaded areas are $80 \%$ confidence interval, the dotted line represents the posterior mean of the spline function and the continuous line marks $y=0$. 
Table 3: Freight attraction model posterior estimates

\begin{tabular}{|c|c|c|c|c|c|c|}
\hline \multirow[b]{2}{*}{ Variable } & \multicolumn{4}{|c|}{ Unpenalized model part } & \multicolumn{2}{|c|}{ Penalized model part } \\
\hline & $\begin{array}{c}\text { Inclusion } \\
\text { prob. } \\
\text { (a) }\end{array}$ & $\begin{array}{l}\text { Mean } \\
\text { (b) }\end{array}$ & $\begin{array}{l}\text { Std. dev. } \\
\text { c }\end{array}$ & $\begin{array}{l}\text { Sign prob. } \\
\text { (d) }\end{array}$ & $\begin{array}{c}\text { Inclusion } \\
\text { prob. } \\
\text { (e) }\end{array}$ & $\begin{array}{l}\text { functional } \\
\text { form } \\
\text { (f) }\end{array}$ \\
\hline $\begin{array}{l}\rho \\
\sigma^{2}\end{array}$ & & $\begin{array}{l}0.2485 \\
0.1338\end{array}$ & $\begin{array}{l}0.0996 \\
0.0191\end{array}$ & 1.0000 & & \\
\hline Regional domestic product per capita & 0.0504 & 0.0206 & 0.1121 & 0.5262 & 0.0358 & \\
\hline W Regional domestic product per capita & 0.0306 & 0.0063 & 0.0508 & 0.5306 & 0.0463 & \\
\hline Manufacturing gross value added & 1.0000 & -2.9145 & 0.3344 & 1.0000 & 1.0000 & \\
\hline W Manufacturing gross value added & 0.9555 & 1.0559 & 0.3658 & 0.9775 & 0.0279 & \\
\hline Population density & 0.0279 & 0.0043 & 0.0386 & 0.5138 & 0.0283 & \\
\hline W Population density & 0.1095 & 0.0688 & 0.3133 & 0.5342 & 1.0000 & 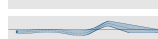 \\
\hline Manufacturing employment & 0.0122 & 0.0016 & 0.0307 & 0.5022 & 0.0136 & \\
\hline W Manufacturing employment & 0.0648 & 0.0324 & 0.1498 & 0.5334 & 0.0099 & \\
\hline Construction employment & 0.0154 & -0.0001 & 0.0299 & 0.5048 & 0.0175 & \\
\hline W Construction employment & 0.0134 & -0.0013 & 0.0365 & 0.5049 & 0.0162 & \\
\hline Market services employment & 0.0251 & -0.0082 & 0.0599 & 0.5317 & 0.0097 & \\
\hline W Market services employment & 0.0229 & 0.0011 & 0.0365 & 0.5032 & 0.0105 & \\
\hline Avg. production of manufacturing units & 0.0379 & -0.0089 & 0.0667 & 0.5171 & 0.5775 & \\
\hline W Avg. production of manufacturing units & 0.0250 & 0.0003 & 0.0367 & 0.5045 & 0.1162 & \\
\hline Degree of urbanization & 0.0164 & -0.0013 & 0.0172 & 0.5090 & 0.0091 & \\
\hline W Degree of urbanization & 0.0215 & -0.0035 & 0.0310 & 0.5236 & 0.0090 & \\
\hline Share of logistic companies & 0.0200 & -0.0007 & 0.0616 & 0.5111 & 0.1157 & \\
\hline W Share of logistic companies & 0.0465 & -0.0158 & 0.0860 & 0.5287 & 0.0103 & \\
\hline Logistic employment (share) & 0.0312 & -0.0068 & 0.0591 & 0.5282 & 0.0275 & \\
\hline W Logistic employment (share) & 0.0388 & -0.0081 & 0.0639 & 0.5111 & 0.0261 & \\
\hline Number of airports & 0.0817 & -0.0336 & 0.1334 & 0.5539 & 0.0187 & \\
\hline W Number of airports & 0.0290 & -0.0034 & 0.0384 & 0.5131 & 0.0079 & \\
\hline Length of road network $(\mathrm{km})$ & 0.0405 & -0.008 & 0.0546 & 0.5348 & 0.0307 & \\
\hline W Length of road network ( $\mathrm{km})$ & 0.0125 & -0.0003 & 0.0268 & 0.5027 & 0.0346 & \\
\hline Number of seaports & 0.0128 & -0.0027 & 0.0322 & 0.5110 & 0.0113 & \\
\hline W Number of seaports & 0.0392 & 0.0089 & 0.0644 & 0.5137 & 0.0119 & \\
\hline Travel time to seaport (min) & 0.0102 & -0.0007 & 0.0154 & 0.5090 & 0.0079 & \\
\hline W Travel time to seaport ( $\min )$ & 0.0771 & -0.0317 & 0.1226 & 0.5533 & 0.0429 & \\
\hline Capital city region & 1.0000 & -0.3645 & 0.0764 & 1.0000 & & \\
\hline W Capital city region & 0.0179 & -0.0028 & 0.0282 & 0.5141 & & \\
\hline Region with large city & 0.0265 & 0.0061 & 0.0276 & 0.5631 & & \\
\hline W Region with large city & 0.0330 & 0.0092 & 0.0489 & 0.5444 & & \\
\hline Rural region & 0.0056 & -0.0016 & 0.0115 & 0.5360 & & \\
\hline W Rural region & 0.0132 & 0.0012 & 0.0184 & 0.5004 & & \\
\hline Border region & 0.0250 & 0.005 & 0.0235 & 0.5580 & & \\
\hline W Border region & 0.3560 & 0.1034 & 0.1427 & 0.7204 & & \\
\hline Objective 1 region & 0.0136 & 0.003 & 0.0158 & 0.5521 & & \\
\hline W Objective 1 region & 0.0835 & 0.0259 & 0.0751 & 0.6019 & & \\
\hline Coastal region & 0.0069 & 0.0018 & 0.0130 & 0.5313 & & \\
\hline W Coastal region & 0.0271 & -0.0058 & 0.0324 & 0.5428 & & \\
\hline
\end{tabular}

Notes: Posterior results based on $\mathbf{W}$ matrix with seven nearest neighbors. The plots in column (f) are all bounded on the $y$-axis at \pm 1 . The shaded areas are $80 \%$ confidence interval, the dotted line represents the posterior mean of the spline function and the continuous line marks $y=0$. 
Table 4: Non-spatial freight generation (a) and attraction (b) model posterior estimates

\begin{tabular}{|c|c|c|c|c|c|c|}
\hline \multicolumn{7}{|c|}{ (a) - Freight Generation } \\
\hline & \multicolumn{4}{|c|}{ Unpenalized model part } & \multicolumn{2}{|c|}{ Penalized model part } \\
\hline Variable & $\begin{array}{l}\text { Inclusion } \\
\text { prob. } \\
\text { (a) }\end{array}$ & $\begin{array}{c}\text { Mean } \\
\text { (b) }\end{array}$ & $\begin{array}{l}\text { Std. dev. } \\
\text { (c) }\end{array}$ & $\begin{array}{c}\text { Sign prob. } \\
\text { (d) }\end{array}$ & $\begin{array}{c}\text { Inclusion } \\
\text { prob. } \\
\text { (e) }\end{array}$ & $\begin{array}{l}\text { functional } \\
\text { form } \\
\text { (f) }\end{array}$ \\
\hline $\begin{array}{l}\text { Moran's I } \\
\sigma^{2}\end{array}$ & & $\begin{array}{l}0.1421 \\
0.1615\end{array}$ & $\begin{array}{l}0.0301 \\
0.0178\end{array}$ & & & \\
\hline Regional domestic product per capita & 0.1644 & 0.0262 & 0.1247 & 0.5451 & 0.1288 & \\
\hline Manufacturing gross value added & 1.0000 & -2.4002 & 0.3339 & 1.0000 & 0.9939 & \\
\hline Population density & 0.4261 & 0.1868 & 0.2690 & 0.7096 & 0.1842 & \\
\hline Manufacturing employment & 0.7092 & 0.3865 & 0.3187 & 0.8511 & 0.0999 & \\
\hline Construction employment & 0.1127 & 0.0010 & 0.0832 & 0.5060 & 0.1126 & \\
\hline Market services employment & 0.2258 & -0.0794 & 0.1907 & 0.6058 & 0.0759 & \\
\hline Avg. production of manufacturing units & 0.1637 & -0.0287 & 0.1452 & 0.5355 & 0.9873 & \\
\hline Degree of urbanization & 0.1016 & -0.0061 & 0.0413 & 0.5289 & 0.0647 & \\
\hline Share of logistic companies & 0.1054 & -0.0042 & 0.0829 & 0.5147 & 0.1663 & \\
\hline Logistic employment (share) & 0.1386 & -0.0183 & 0.1093 & 0.5286 & 0.1224 & \\
\hline Number of airports & 0.2341 & -0.0746 & 0.1934 & 0.5928 & 0.0995 & \\
\hline Length of road network $(\mathrm{km})$ & 0.1671 & -0.0225 & 0.1017 & 0.5516 & 0.2583 & \\
\hline Number of seaports & 0.0988 & 0.0012 & 0.0545 & 0.5066 & 0.0664 & \\
\hline Travel time to seaport ( $\mathrm{min}$ ) & 0.0766 & -0.0011 & 0.0313 & 0.5009 & 0.0595 & \\
\hline Capital city region & 0.6322 & -0.1312 & 0.1138 & 0.8463 & & \\
\hline Region with large city & 0.1810 & 0.0245 & 0.0578 & 0.6171 & & \\
\hline Rural region & 0.0803 & -0.0073 & 0.0296 & 0.5588 & & \\
\hline Border region & 0.5173 & 0.0764 & 0.0792 & 0.8017 & & \\
\hline Objective 1 region & 0.0521 & 0.0031 & 0.0180 & 0.5426 & & \\
\hline Coastal region & 0.0381 & 0.0010 & 0.0134 & 0.5107 & & \\
\hline \multicolumn{7}{|c|}{ (b) - Freight Attraction } \\
\hline & \multicolumn{4}{|c|}{ Unpenalized model part } & \multicolumn{2}{|c|}{ Penalized model part } \\
\hline Variable & $\begin{array}{l}\text { Inclusion } \\
\text { prob. } \\
\text { (a) }\end{array}$ & $\begin{array}{c}\text { Mean } \\
\text { (b) }\end{array}$ & $\begin{array}{l}\text { Std. dev. } \\
\text { (c) }\end{array}$ & $\begin{array}{c}\text { Sign prob. } \\
\text { (d) }\end{array}$ & $\begin{array}{c}\text { Inclusion } \\
\text { prob. } \\
\text { (e) }\end{array}$ & $\begin{array}{l}\text { functional } \\
\text { form } \\
\text { (f) }\end{array}$ \\
\hline Moran's I & & 0.1415 & 0.0302 & & & \\
\hline$\sigma^{2}$ & & 0.1728 & 0.0197 & & & \\
\hline Regional domestic product per capita & 0.1256 & 0.0120 & 0.0940 & 0.5136 & 0.0944 & \\
\hline Manufacturing gross value added & 1.0000 & -2.6084 & 0.3482 & 1.0000 & 1.0000 & \\
\hline Population density & 0.2522 & 0.0768 & 0.1800 & 0.5970 & 0.2372 & \\
\hline Manufacturing employment & 0.6416 & 0.4051 & 0.3549 & 0.8335 & 0.1242 & \\
\hline Construction employment & 0.1566 & -0.0154 & 0.1172 & 0.5153 & 0.1077 & \\
\hline Market services employment & 0.3242 & -0.1280 & 0.2423 & 0.6459 & 0.0710 & \\
\hline Avg. production of manufacturing units & 0.1385 & -0.0228 & 0.1380 & 0.5387 & 0.9744 & \\
\hline Degree of urbanization & 0.0929 & -0.0065 & 0.0533 & 0.5303 & 0.0862 & \\
\hline Share of logistic companies & 0.1344 & -0.0116 & 0.1055 & 0.5224 & 0.1548 & \\
\hline Logistic employment (share) & 0.1415 & -0.0157 & 0.1078 & 0.5248 & 0.1538 & \\
\hline Number of airports & 0.2341 & -0.0522 & 0.1626 & 0.5720 & 0.0749 & \\
\hline Length of road network $(\mathrm{km})$ & 0.1255 & -0.0142 & 0.0839 & 0.5318 & 0.2073 & \\
\hline Number of seaports & 0.1153 & -0.0075 & 0.0696 & 0.5193 & 0.0531 & \\
\hline Travel time to seaport ( $\min )$ & 0.0961 & -0.0029 & 0.0358 & 0.5116 & 0.0572 & \\
\hline Capital city region & 0.7972 & -0.1889 & 0.1109 & 0.9257 & & \\
\hline Region with large city & 0.1413 & 0.0202 & 0.0539 & 0.6062 & & \\
\hline Rural region & 0.0629 & -0.0045 & 0.0241 & 0.5474 & & \\
\hline Border region & 0.4177 & 0.0638 & 0.0798 & 0.7660 & & \\
\hline Objective 1 region & 0.0515 & 0.0023 & 0.0161 & 0.5273 & & \\
\hline Coastal region & 0.0652 & 0.0043 & 0.0219 & 0.5509 & & \\
\hline
\end{tabular}

Notes: The plots in column (f) are all bounded on the $y$-axis at \pm 1 . The shaded areas are $80 \%$ confidence interval, the dotted line represents the posterior mean of the spline function and the continuous line marks $y=0$. 


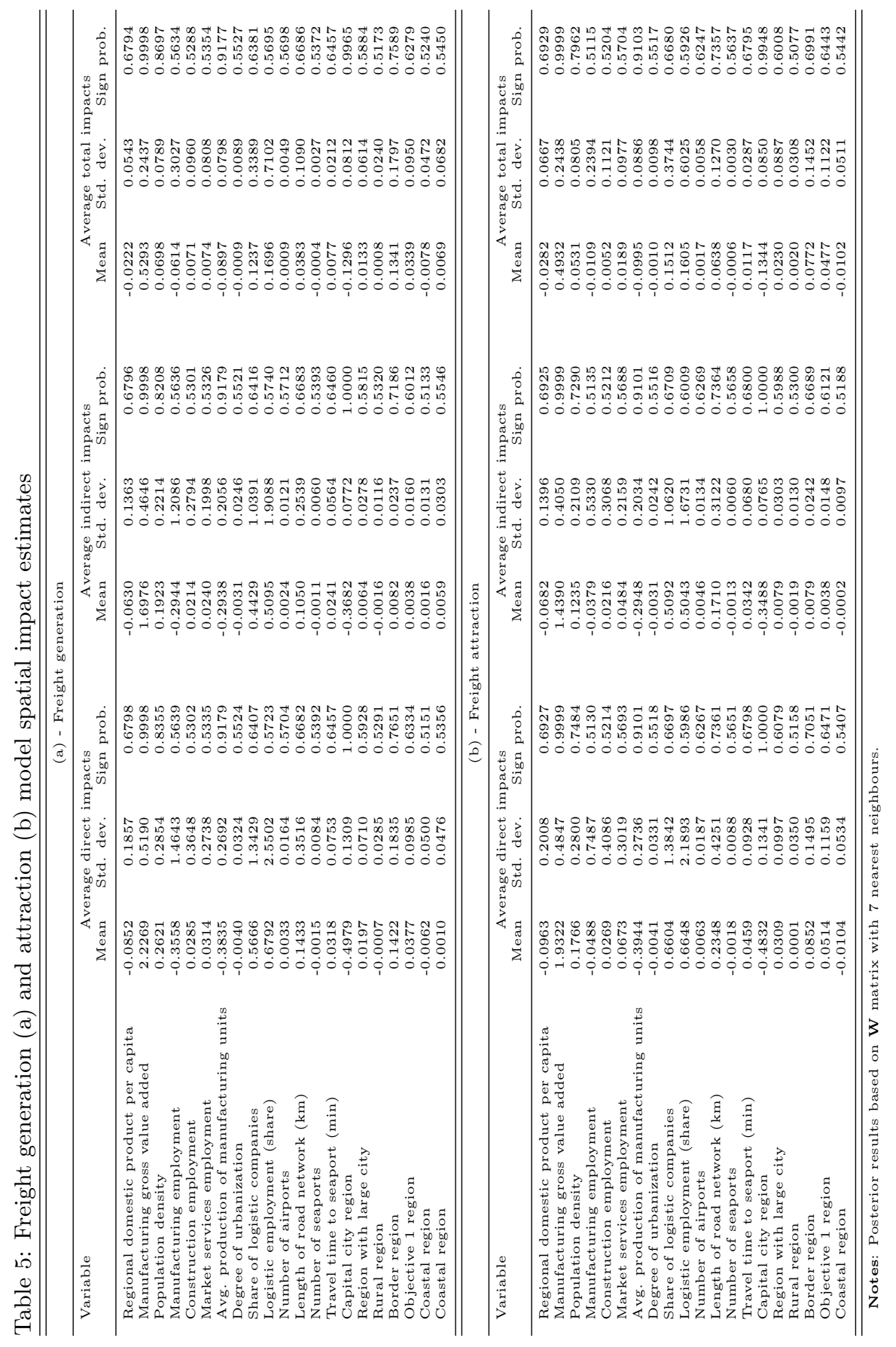




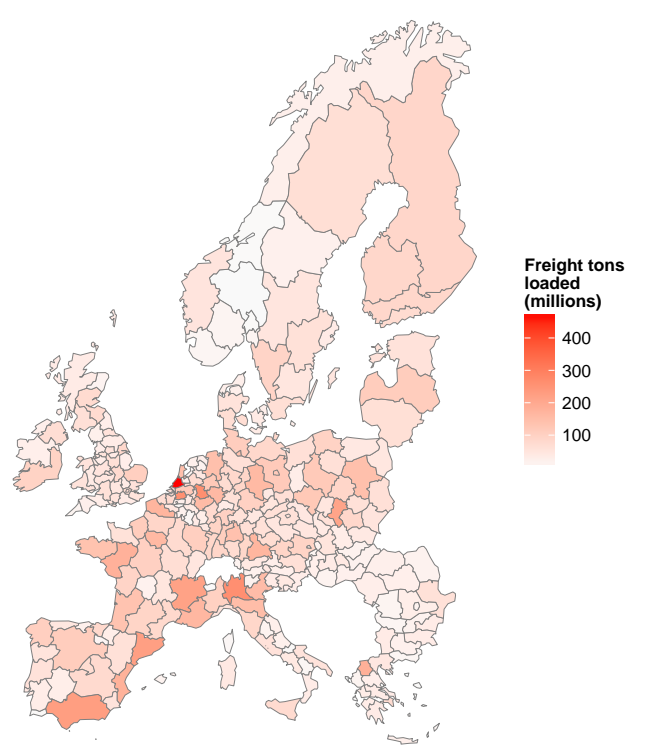

(a)

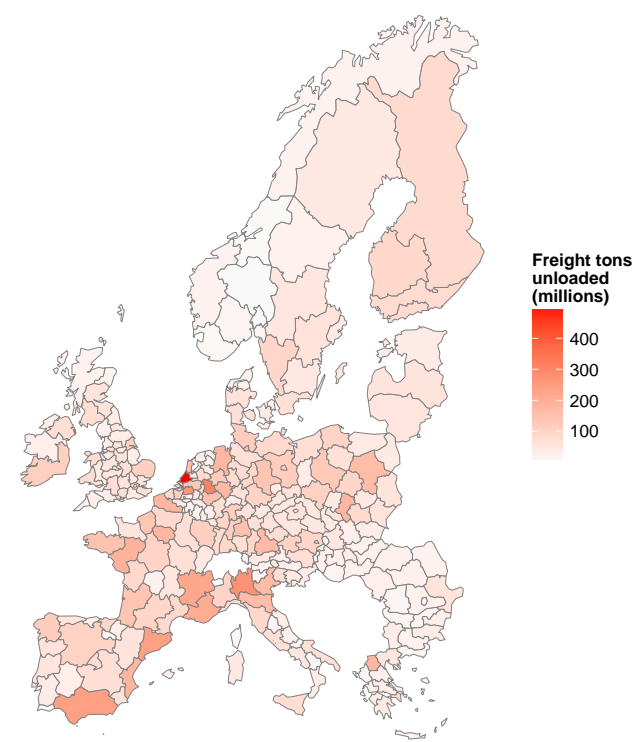

(b)

Fig. 1: Average yearly million tons of freight generated by (a) and attracted to (b) NUTS-2 regions, 2010 $-2014$. 
Fig. 2: Functional fit of the penalized spline functions for the two model terms with the highest posterior inclusion probability, in the freight generation (i - ii) and attraction models (iii - iv), respectively.

Freight generation

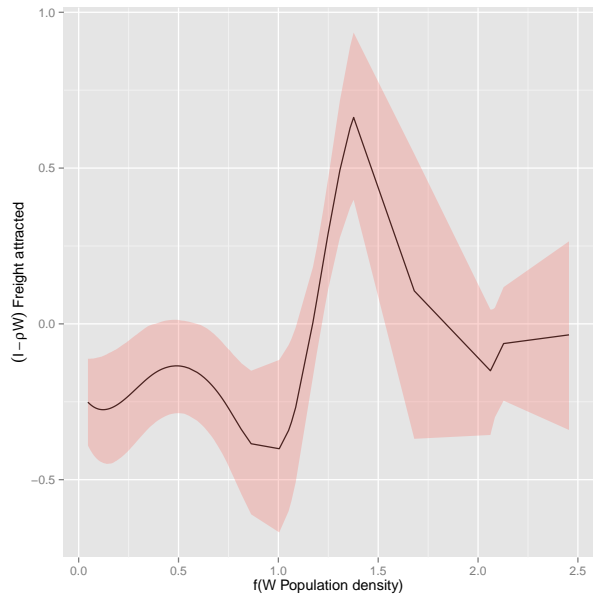

Inclusion prob. $=0.9946$

(i)

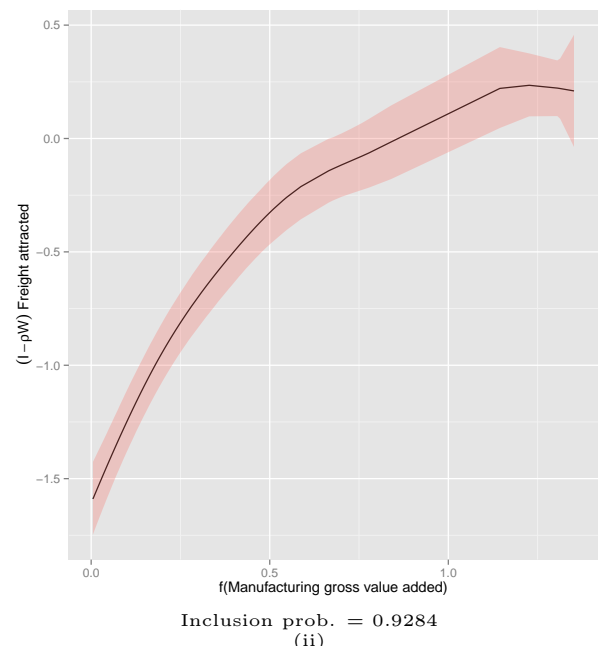

(ii)
Freight attraction
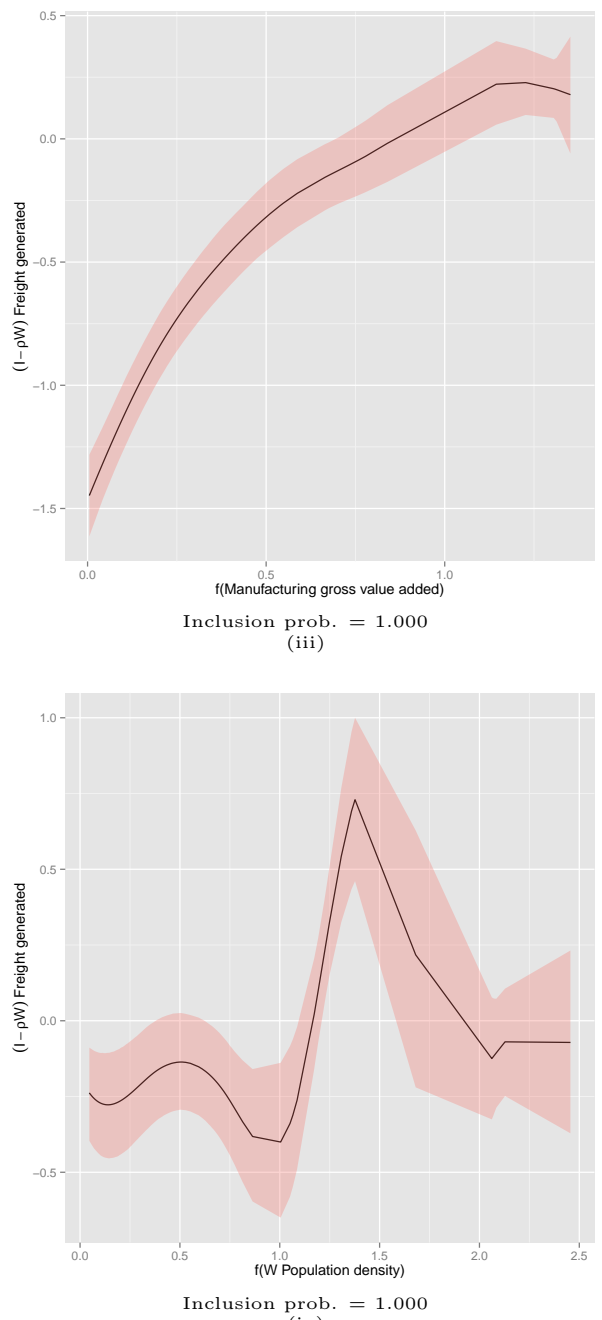

(iv)

Notes: Posterior results based on $\mathbf{W}$ matrix with seven nearest neighbors. The shaded areas are $80 \%$ confidence interval and an of the spline function. 


\section{Appendix A}

We assume that the unknown function $f_{m}\left(\boldsymbol{v}_{m}\right)$ can be approximated by a polynomial splines of degree $D_{m} \cdot f_{m}(\cdot)$ is defined over a set of $\chi_{m}$ knots. The set of knots consist of $L_{m}$ equally spaced over the range spanned by $\min \left(\boldsymbol{v}_{m}\right)$ and $\max \left(\boldsymbol{v}_{m}\right)$, and $2 D_{m}$ support knots.

More formally, let $\chi_{m, p_{m}} \in \chi_{m}$ be a typical knot, with $p_{m}=1, \ldots, P_{m}$ and $P_{m}=L_{m}+2 D_{m}$. Then $\chi_{m}$ is constructed so that:

$$
\begin{aligned}
& \qquad \boldsymbol{\chi}_{m}=\left[\chi_{m, 1}, \ldots, \chi_{m, P_{m}}\right] \\
& \text { where } \\
& \min \left(\boldsymbol{v}_{m}\right)=\chi_{m, 1}=\cdots=\chi_{m, D_{m}} \\
& \quad \chi_{m, D_{m}+1}<\cdots<\chi_{m, L_{m}+D_{m}} \\
& \quad \chi_{m, L_{m}+D_{m}+1}=\cdots=\chi_{m, P_{m}}=\max \left(\boldsymbol{v}_{m}\right)-
\end{aligned}
$$

Thus we can approximate the nonlinear function $f_{m}(\cdot)$ through $L_{m}=P_{m}+2 D_{m}$ basis functions (see the seminal work by DeBoor 1978):

$$
f_{m}\left(\boldsymbol{v}_{m}\right) \approx \overline{\mathbf{Z}}_{m} \overline{\boldsymbol{\beta}}_{m}
$$

where $\overline{\mathbf{Z}}_{m}$ is a $n \times P_{m}$ matrix, where each column corresponds to a basis function and $\overline{\boldsymbol{\beta}}_{m}$ is the corresponding $P_{m} \times 1$ vector of parameters.

Now let $\overline{\boldsymbol{z}}_{i}$ be the $i$-th row of $\overline{\mathbf{Z}}_{m}$ and $v_{i, m}$ the $i$-th element of $\boldsymbol{v}_{i, m}$. Then we can write:

$$
f_{m}\left(v_{i, m}\right) \approx \sum_{p_{m}=1}^{P_{m}} \bar{\beta}_{m, p_{m}} B^{D_{m}}\left(v_{i, m}\right)
$$

where $B^{D_{m}}(\cdot)$ denotes a basis function of degree $D_{m}$. These basis functions are defined recursively over $d_{m}=0, \ldots, D_{m}$ as (see DeBoor 1978 for further details):

$$
\begin{aligned}
\text { for } d_{m} & =1, \ldots, D_{m}: \\
B^{d_{m}}\left(v_{i, m}\right) & =\frac{v_{i, m}-\chi_{m, p_{m}}}{\chi_{m, p_{m}}+d_{m}-\chi_{m, p_{m}}} B^{d_{m}-1}\left(v_{i, m}\right)+\frac{\chi_{m, p_{m}+d_{m}+1}-v_{i, m}}{\chi_{m, p_{m}+d_{m}+1}-\chi_{m, p_{m}+1}} B^{d_{m}-1}\left(v_{i, m}\right) \\
\text { for } d_{m} & =0: \\
B^{0}\left(v_{i, m}\right) & =\mathbb{1}_{\left[\chi_{m, p_{m}}, \chi_{m, p_{m}+1}\right]}\left(v_{i, m}\right)= \begin{cases}1 & \chi_{m, p_{m}} \leq v_{i, m}<\chi_{m, p_{m}+1} \\
0 & \text { otherwise }\end{cases}
\end{aligned}
$$

where basis functions of the first degree are denoted by $\mathbb{1}$. These take on values of one between knot points $\chi_{m, p_{m}}$ and $\chi_{m, p_{m}+1}$ otherwise they are zero. Higher order B-splines are defined recursively. Eq. (31) implies that each basis function of degree $D_{m}$ is defined only over a local interval, i.e. only over the neighbouring $2 D_{m}$ knots.

The derivative of a B-spline is a B-spline itself, comprised of piecewise polynomials. The derivative of a basis function is defined as:

$$
\frac{\partial}{\partial v_{i, m}} B^{D_{m}}\left(v_{i, m}\right)=D_{m}\left(\frac{B^{D_{m}-1}\left(v_{i, m}\right)}{\chi_{m, p_{m}+D_{m}}-\chi_{m, p_{m}}}-\frac{B^{D_{m}-1}\left(v_{i, m}\right)}{\chi_{m, p_{m}+D_{m}+1}-\chi_{m, p_{m}+1}}\right)
$$

which can be expressed as a spline of degree $D_{m}-1$.

\section{Appendix B}


Table B1: List of countries and NUTS-2 regions

\begin{tabular}{|c|c|c|c|c|c|c|c|}
\hline Code & Region name & Code & Region name & Code & Region name & Code & Region name \\
\hline & Austria & & Denmark & & Italy & & Sweden \\
\hline AT11 & Burgenland (AT) & DK01 & Hovedstaden & ITC1 & Piemonte & SE11 & Stockholm \\
\hline $\mathrm{AT} 12$ & Niederösterreich & $\mathrm{DKO} 2$ & Sjælland & ITC2 & Valle d'Aosta & SE12 & Östra Mellansverige \\
\hline AT13 & Wien & DKO3 & Syddanmark & ITC3 & Liguria & $\mathrm{SE} 21$ & Småland med öarna \\
\hline AT21 & Kärnten & DK04 & Midtjylland & ITC4 & Lombardia & $\mathrm{SE} 22$ & Sydsverige \\
\hline AT22 & Steiermark & DK05 & Nordjylland & ITF 1 & Abruzzo & $\mathrm{SE} 23$ & Västsverige \\
\hline AT31 & Oberösterreich & & Estonia & ITF2 & Molise & SE31 & Norra Mellansverige \\
\hline AT32 & Salzburg & EEO0 & Eesti & ITF 3 & Campania & SE32 & Mellersta Norrland \\
\hline AT33 & Tirol & & Greece & ITF 4 & Puglia & SE33 & Övre Norrland \\
\hline AT34 & Vorarlberg & EL11 & Anatoliki Makedonia, Thraki & ITF5 & Basilicata & & Slovenia \\
\hline & Belgium & EL12 & Kentriki Makedonia & ITF6 & Calabria & SI01 & Vzhodna Slovenija \\
\hline BE10 & Région de Bruxelles-Capitale & EL13 & Dytiki Makedonia & ITG1 & Sicilia & SIO2 & Zahodna Slovenija \\
\hline BE21 & Prov. Antwerpen & EL14 & $\begin{array}{l}\text { Dyessalia } \\
\text { Thedonia }\end{array}$ & ITG2 & Sardegna & 5102 & $\begin{array}{l}\text { Zanodna } \\
\text { Slovakia }\end{array}$ \\
\hline $\mathrm{BE} 22$ & Prov. Limburg (BE) & EL21 & Ipeiros & ITH1 & Provincia Autonoma di Bolzano & SK01 & Bratislavský kraj \\
\hline $\mathrm{BE} 23$ & Prov. Oost-Vlaanderen & EL22 & Ionia Nisia & ITH2 & Provincia Autonoma di Trento & SK02 & Západné Slovensko \\
\hline $\mathrm{BE} 24$ & Prov. Vlaams-Brabant & EL23 & Dytiki Ellada & ITH3 & Veneto & SK03 & Stredné Slovensko \\
\hline $\mathrm{BE} 25$ & Prov. West-Vlaanderen & EL24 & Sterea Ellada & ITH 4 & Friuli-Venezia Giulia & SK04 & Východné Slovensko \\
\hline BE31 & Prov. Brabant Wallon & EL25 & Peloponnisos & $\begin{array}{l}\text { ITH5 } \\
\text { ITH }-40\end{array}$ & Emilia-Romagna & ShO4 & United Kingdom \\
\hline BE32 & Prov. Hainaut & EL30 & Attiki & ITI1 & Toscana & UKC1 1 & Tees Valley, Durham \\
\hline BE33 & Prov. Liège & EL41 & Voreio Aigaio & ITI2 & Umbria & $\mathrm{UKC} 2$ & Northumberland, Tyne and Wear \\
\hline BE34 & Prov. Luxembourg (BE) & EL42 & Notio Aigaio & ITI3 & Marche & UKD1 & Cumbria \\
\hline BE35 & Prov. Namur & EL43 & Kriti & ITI4 & Lazio & UKD3 & Greater Manchester \\
\hline & Bulgaria & & Spain & & Latvia & UKD4 & Lancashire \\
\hline BG31 & Severozapaden & ES11 & Galicia & LTо0 & Lietuva Lávia & UKD6 & Cheshire \\
\hline BG32 & Severen tsentralen & ES12 & Principado de Asturias & & Luxembourg & UKD7 & Merseyside \\
\hline BG33 & Severoiztochen & ES13 & Cantabria & LU00 & Luxembourg & UKE1 1 & East Yorkshire and \\
\hline BG34 & Yugoiztochen & ES21 & País Vasco & & Lithuania & & Northern Lincolnshire \\
\hline BG41 & Yugozapaden & ES22 & Comunidad Foral de Navarra & LVoo & Latvija & UKE2 & North Yorkshire \\
\hline $\mathrm{BG} 42$ & Yuzhen tsentralen & ES23 & La Rioja & & Netherlands & UKE3 & South Yorkshire \\
\hline & Czech Republic & ES24 & Aragón & NL11 & Groningen & UKE 4 & West Yorkshire \\
\hline CZ01 & Praha & ES30 & Comunidad de Madrid & NL12 & Friesland (NL) & UKF1 1 & Derbyshire, Nottinghamshire \\
\hline $\mathrm{CZO2}$ & Strední Cechy & ES41 & Castilla y León & NL13 & Drenthe & UKF2 & Leicestershire, Rutland and \\
\hline CZ03 & Jihozápad & ES42 & Castilla-la Mancha & NL21 & Overijssel & & Northamptonshire \\
\hline CZ04 & Severozápad & ES43 & Extremadura & NL22 & Gelderland & UKF3 & Lincolnshire \\
\hline CZO5 & Severovýchod & $\begin{array}{l}\text { ES } 43 \\
\text { ES51 }\end{array}$ & $\begin{array}{l}\text { Extremadura } \\
\text { Cataluña }\end{array}$ & NL23 & Flevoland & UKG1 & $\begin{array}{l}\text { Herefordshire, Worcestershire and } \\
\text { Hereoris }\end{array}$ \\
\hline CZ06 & Jihovýchod & ES52 & Comunidad Valenciana & NL31 & Utrecht & & Warwickshire \\
\hline CZ07 & Strední Morava & ES53 & $\begin{array}{l}\text { Illes Balears } \\
\text {. }\end{array}$ & NL32 & Noord-Holland & UKG2 & Shropshire, Staffordshire \\
\hline CZ08 & Moravskoslezsko & ES61 & Andalucía & NL33 & Zuid-Holland & UKG3 & West Midlands \\
\hline & Germany & & Finland & NL34 & Zeeland & UKH1 & East Anglia \\
\hline DE11 & Stuttgart & FI19 & Länsi-Suomi & NL41 & Noord-Brabant & UKH2 & Bedfordshire, Hertfordshire \\
\hline $\mathrm{DE} 12$ & Karlsruhe & FI1B & Helsinki-Uusimaa & NL42 & Limburg (NL) & UKH3 & Essex \\
\hline $\mathrm{DE} 13$ & Freiburg & FI1C & Etelä-Suomi & & Poland & UKI1 & Inner London \\
\hline DE14 & Tübingen & FI1D & Pohjois- ja Itä-Suomi & PL11 & Lódzkie & UKI2 & Outer London \\
\hline $\mathrm{DE} 21$ & Oberbayern & & France & PL12 & Mazowieckie & UKJ1 & Berkshire, Buckinghamshire and \\
\hline DE22 & Niederbayern & FR10 & Île de France & PL21 & Malopolskie & & Oxfordshire \\
\hline $\mathrm{DE} 23$ & Oberpfalz & FR21 & Champagne-Ardenne & PL22 & Slaskie & UKJ2 & Surrey, East, West Sussex \\
\hline $\mathrm{DE} 24$ & Oberfranken & FR22 & Picardie & PL31 & Lubelskie & UKJ3 & Hampshire, Isle of Wight \\
\hline $\mathrm{DE} 25$ & Mittelfranken & FR23 & Haute-Normandie & PL32 & Podkarpackie & UKJ4 & Kent \\
\hline DE26 & Unterfranken & FR24 & Centre (FR) & PL33 & Swietokrzyskie & UKK1 & Gloucestershire, Wiltshire, Bristol \\
\hline $\mathrm{DE} 27$ & Schwaben & FR25 & Basse-Normandie & PL34 & Podlaskie & UKK2 & Dorset, Somerset \\
\hline $\begin{array}{l}\text { DE2 } \\
\text { DE30 }\end{array}$ & Berlin & FR26 & $\begin{array}{l}\text { Basse-Normandie } \\
\text { Bourgogne }\end{array}$ & PL41 & Wielkopolskie & UKK3 & Cornwall, Isles of Scilly \\
\hline $\mathrm{DE} 40$ & Brandenburg & FR30 & Nord - Pas-de-Calais & PL42 & Zachodniopomorskie & UKK4 & Devon \\
\hline $\begin{array}{l}\text { DE40 } \\
\text { DE50 }\end{array}$ & Bremen & FR41 & Lorraine & PL43 & Lubuskie & $\begin{array}{l}\text { UKL1 } \\
\text { UKL } 19\end{array}$ & West Wales, The Valleys \\
\hline $\mathrm{DE} 60$ & Hamburg & FR42 & Alsace & PL51 & Dolnoslaskie & UKL2 & East Wales \\
\hline DE71 & Darmstadt & FR43 & Franche-Comté & PL52 & Opolskie & UKM2 & Eastern Scotland \\
\hline DE72 & Gießen & FR51 & Pays de la Loire & PL61 & Kujawsko-Pomorskie & UKM3 & South Western Scotland \\
\hline DE73 & Kassel & FR52 & Bretagne & PL62 & Warminsko-Mazurskie & UKM5 & North Eastern Scotland \\
\hline DE 80 & Mecklenburg-Vorpommern & FR53 & Poitou-Charentes & PL63 & Pomorskie & UKM6 & Highlands, Islands \\
\hline DE91 & Braunschweig & FR61 & Aquitaine & & Portugal & UKNO & Northern Ireland (UK) \\
\hline DE92 & Hannover & FR62 & Midi-Pyrénées & PT11 & Norte & & \\
\hline DE93 & Lüneburg & FR63 & Limousin & PT15 & Algarve & & \\
\hline DE94 & Weser-Ems & FR71 & Rhône-Alpes & PT16 & Centro (PT) & & \\
\hline DEA1 & Düsseldorf & FR72 & Auvergne & PT17 & Área Metropolitana de Lisboa & & \\
\hline $\mathrm{DEA} 2$ & Köln & FR81 & Languedoc-Roussillon & PT18 & Alentejo & & \\
\hline DEA3 & Münster & FR82 & Provence-Alpes-Côte d'Azur & & Romania & & \\
\hline $\begin{array}{l}\text { DEAS } \\
\text { DEA4 }\end{array}$ & Detmold & FR83 & 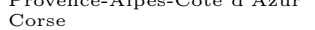 & RO11 & Nord-Vest & & \\
\hline DEA5 & Arnsberg & & Hungary & $\mathrm{RO} 12$ & Centru & & \\
\hline DEB 1 & Koblenz & HU10 & Közép-Magyarország & RO21 & Nord-Est & & \\
\hline $\mathrm{DEB} 2$ & Trier & HU21 & Közép-Dunántúl & $\mathrm{RO} 22$ & Sud-Est & & \\
\hline DEB3 & Rheinhessen-Pfalz & HU22 & Nyugat-Dunántúl & RO31 & Sud - Muntenia & & \\
\hline DECO & $\begin{array}{l}\text { Saarland } \\
\text { S }\end{array}$ & HU 23 & Dél-Dunántúl & RO32 & Bucuresti - Ilfov & & \\
\hline DED2 & Dresden & HU31 & Észak-Magyarország & RO41 & Sud-Vest Oltenia & & \\
\hline DED4 & Chemnitz & HU 32 & Észak-Alföld & $\mathrm{RO} 42$ & Vest & & \\
\hline DED 5 & Leipzig & HU33 & Dél-Alföld & & & & \\
\hline DEEO & Sachsen-Anhalt & & Ireland & & & & \\
\hline DEFO & Schleswig-Holstein & IE01 & Border, Midland, We & & & & \\
\hline DEGO & Thüringen & IE02 & Southern, Eastern & & & & \\
\hline
\end{tabular}


Table B2: Summary statistics for the covariates

\begin{tabular}{lrrrr}
\hline \hline Variable & Mean & Std. dev. & Min & Max \\
\hline Freight generated (1,000t) & 0.66 & 0.55 & 0.01 & 4.66 \\
Freight attracted (1,000t) & 0.69 & 0.58 & 0.02 & 4.99 \\
\hline Regional domestic product per capita & 0.22 & 0.26 & 0.01 & 2.56 \\
Manufacturing gross value added & 0.21 & 0.22 & 0.01 & 1.35 \\
Population density & 0.34 & 0.85 & 0.01 & 9.07 \\
Manufacturing employment & 0.08 & 0.02 & 0.03 & 0.16 \\
Construction employment & 0.26 & 0.04 & 0.13 & 0.48 \\
Market services employment & 0.31 & 0.06 & 0.12 & 0.45 \\
Avg. production of manufacturing units & 0.48 & 0.61 & 0.00 & 3.12 \\
Degree of urbanization & 0.40 & 1.11 & 0.00 & 17.28 \\
Share of logistic companies & 0.05 & 0.03 & 0.00 & 0.14 \\
Logistic employment (share) & 0.03 & 0.01 & 0.00 & 0.12 \\
Number of airports & 1.59 & 1.78 & 0.00 & 15.00 \\
Length of road network (km) & 0.15 & 0.15 & 0.00 & 1.05 \\
Number of seaports & 2.25 & 4.54 & 0.00 & 34.00 \\
Travel time to seaport (min) & 0.59 & 0.83 & 0.01 & 3.00 \\
Capital city region & 0.16 & 0.37 & 0.00 & 1.00 \\
Region with large city & 0.72 & 0.45 & 0.00 & 1.00 \\
Rural region & 0.66 & 0.48 & 0.00 & 1.00 \\
Border region & 0.53 & 0.50 & 0.00 & 1.00 \\
Objective 1 region & 0.34 & 0.47 & 0.00 & 1.00 \\
Coastal region & 0.47 & 0.50 & 0.00 & 1.00 \\
\hline \hline
\end{tabular}



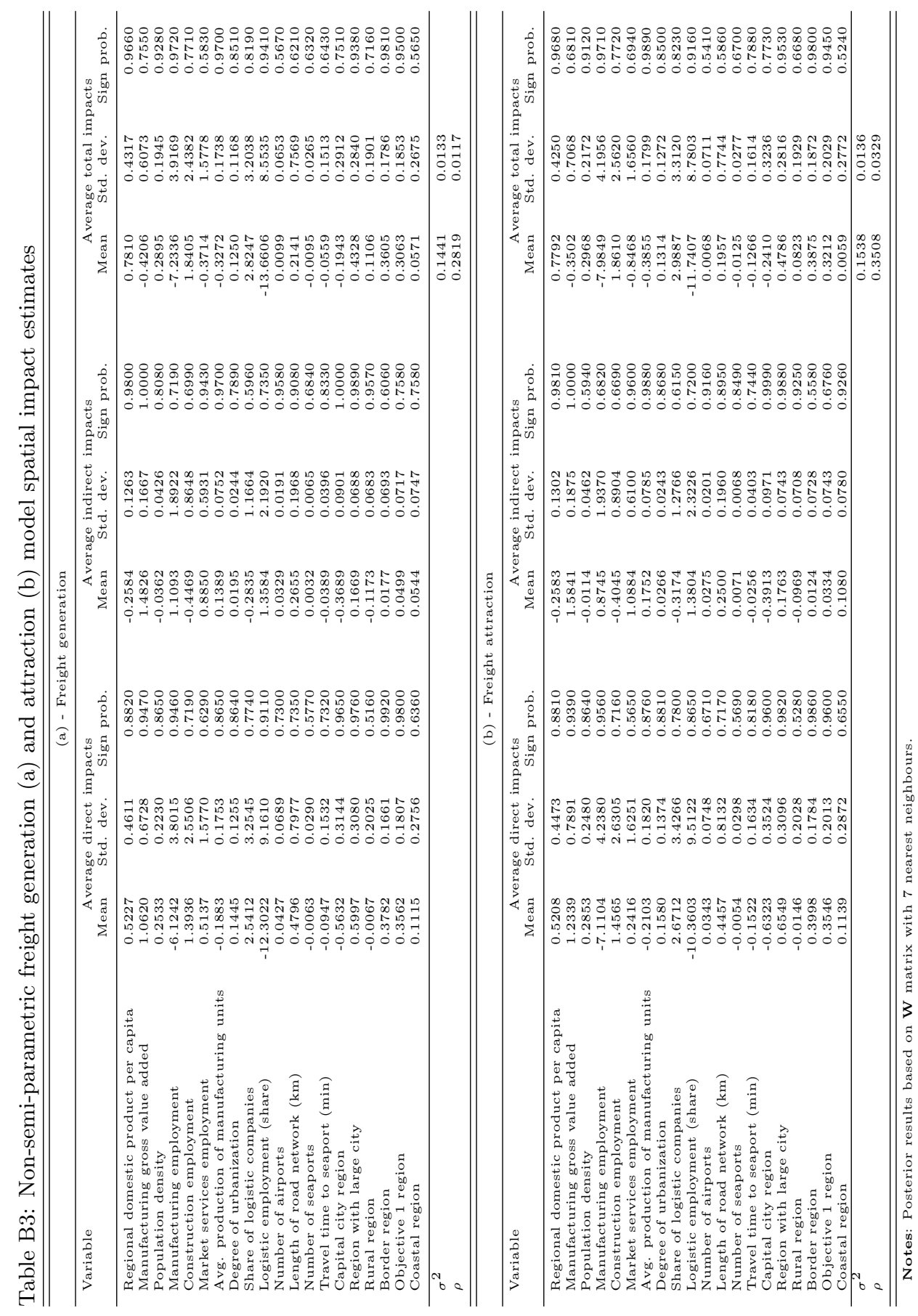